\title{
Integrated Pathways of COX-2 and mTOR: Roles in Cell Sensing and Alzheimer's Disease
}

\author{
Arti Tyagi', Mohammad A. Kamal ${ }^{2,3}$ and Nitesh Kumar Poddar ${ }^{4 *}$ \\ ${ }^{1}$ Department of Biochemical Engineering and Biotechnology, Indian Institute of Technology Delhi, New Delhi, India, ${ }^{2}$ King \\ Fahad Medical Research Center, King Abdulaziz University, Jeddah, Saudi Arabia, ${ }^{3}$ Enzymoics, Hebersham, NSW, Australia, \\ ${ }^{4}$ Department of Biosciences, Manipal University Jaipur, Jaipur, India
}

\section{OPEN ACCESS}

Edited by:

Fangyu Peng,

University of Texas Southwestern Medical Center, United States

Reviewed by:

Gabriela Alejandra Salvador, Universidad Nacional del Sur,

Argentina

Marco Onofri,

G. D'Annunzio University

of Chieti-Pescara, Italy

*Correspondence:

Nitesh Kumar Poddar

niteshkumar.poddar@

jaipur.manipal.edu;

niteshpoddar@gmail.com

Specialty section:

This article was submitted to

Neurodegeneration,

a section of the journal

Frontiers in Neuroscience

Received: 12 February 2020

Accepted: 08 June 2020

Published: 09 July 2020

Citation:

Tyagi A, Kamal MA and Poddar NK (2020) Integrated Pathways of COX-2 and mTOR: Roles in Cell Sensing and Alzheimer's

Disease. Front. Neurosci. 14:693. doi: 10.3389/fnins.2020.00693
Cyclooxygenases (COX) are enzymes catalyzing arachidonic acid into prostanoids. COX exists in three isoforms: COX-1, 2, and 3. COX-1 and COX-2 have been widely studied in order to explore and understand their involvement in Alzheimer's disease $(A D)$, a progressive neuroinflammatory dementia. COX-2 was traditionally viewed to be expressed only under pathological conditions and to have detrimental effects in $A D$ pathophysiology and neurodegeneration. However, an increasing number of reports point to much more complex roles of COX-2 in AD. Mammalian/mechanistic target of rapamycin (mTOR) has been considered as a hub which integrates multiple signaling cascades, some of which are also involved in AD progression. COX-2 and mTOR are both involved in environmental sensing, growth, and metabolic processes of the cell. They are also known to act in cooperation in many different cancers and thus, their role together in normal cellular functions as well as AD has been explored in this review. Some of the therapeutic approaches targeting COX-2 and mTOR in AD and cancer are also discussed.

Keywords: COX, neuro-inflammatory, Alzheimer's, mTOR, cellular pathways

\section{CYCLOOXYGENASE AND ITS ISOFORMS}

Cyclooxygenase-2 (COX-2) is an isoform of the cyclooxygenase enzyme family, along with COX1 and COX-3, which are involved in the synthesis of prostanoids (eicosanoid sub-class) from an essential fatty acid, namely arachidonic acid (AA). AA is first released by the action of phospholipase A2 (PLA2) from plasma membranephospholipids, which acts at the sn-2 position of the phospholipid backbone (Engelking, 2015; Hanna and Hafez, 2018). PLA2 activity is stimulated by microbial products, thrombin, immunoglobulins, etc., whereas anti-inflammatory glucocorticoids are known to inhibit it (Engelking, 2015). Out of the $20+$ different types of PLA2s known to occur, type IIA secretory PLA2 and type IV cytosolic PLA2 $\alpha$ have been shown to be coupled with COX-2 in different cell types. These two subclasses of enzymes have also exhibited cross-talk amongst themselves (Murakami et al., 1997; Balsinde et al., 1998; Bidgood et al., 2000; Sun et al., 2010). However, there are views that sufficient and conclusive data is still not present to establish a clear relationship between secretory PLA2 and eicosanoid signaling (Burke and Dennis, 2009). 
Once AA is released, it is further metabolized by either enzymatic or non-enzymatic processes. Four different enzymatic pathways can act on AA: cyclooxygenase, lipoxygenase, anandamide, and cytochrome p450, resulting in different kinds of eicosanoids (Figure 1). Both COX-1 and COX-2 are part of the cyclooxygenase pathway, giving rise to prostanoids such as prostaglandin (PG) $\mathrm{E}_{2}, \mathrm{PGF}_{2} \alpha, \mathrm{PGD}_{2}, \mathrm{PGI}_{2}$ (prostacyclin), and thromboxane (TX) A2. Prostanoids are a part of vasoactive lipids that act as local hormones and play crucial roles in normal physiology as well as certain pathophysiological states. The COX enzymes were popularized in 1971 upon demonstrating that non-steroidal anti-inflammatory drugs (NSAIDs) exert their potent anti-inflammatory properties via inhibition of COX. Since then, a lot of research has been dedicated to this unique enzyme and the various roles it plays in human physiology. Now, it has been established that NSAIDs also affect many other molecules, but COX remains an important player in various conditions, including certain neuropathologies. Some of these pathologies are also found to be epigenetically regulated as faulty DNA hypermethylation causes transcriptional silencing of COX-2 gene (Kikuchi et al., 2002; Ma et al., 2004).

COX is an integral membrane glycoprotein that carries out the first two committed steps of the prostanoid synthesis pathway: cyclooxygenation and peroxidation. Thus, it's a bifunctional enzyme with a homodimeric structure and a single heme, involved in both the catalytic steps, situated in the middle of the two active sites of the enzyme (Rouzer and Marnett, 2009). In cyclooxygenation, two oxygen molecules are added to AA, forming the cyclic PGG2 (Prostaglandin G2) and later PGH2 (Prostaglandin H2) in the peroxidation step. $\mathrm{PGH} 2$ is an unstable intermediate that is acted upon by specific synthases and isomerases giving rise to different PGs and TX in a cell-specific manner (Clària, 2003). The COX isoforms are encoded on different chromosomes and have a lot of differences in their structural and regulatory organization, although they share a $60 \%$ amino acid sequence homology in their respective proteins (Clària, 2003). COX-2 gene has many regulatory sequences, like a TATA box, two NF$\mathrm{\kappa B}$ sites, a NF-IL6 motif, a CRE motif, and an E box, among others, which are absent in COX-1 gene (Clària, 2003; Kang et al., 2007). Many studies have been conducted in this regard; for example, CREB and Ets family-proteins (Ets-1 and Elk-1) were found to upregulate COX-2 expression in pancreatic $\beta$ cells. A detailed account of the different transcriptional factors involved in COX-2 regulation in different cell types has been given by Kang et al. (2007). This is keeping in line with the fact that COX-1 is generally constitutively expressed (Minghetti, 2004; Hoozemans et al., 2008), whereas COX-2 is induced in response to inflammatory reactions (Clària, 2003). Thus, COX-1 is often associated with PG synthesis under normal physiological conditions leading to phenomena like platelet aggregation, renal perfusion maintenance, and gastric cytoprotection. However, it has been found that COX-2 is also expressed in the kidneys, brain, and testes under physiological conditions along with COX1 (Minghetti, 2004; Hoozemans et al., 2008). Specifically, in the brain, COX-2 has been proposed to influence memory, sensory integration, and autonomic regulation in the central nervous system (CNS) (Kaufmann et al., 1997). COX-3, on the other hand, is most populated in the cerebral cortex region of the brain and its enzymatic activity is inhibited by acetaminophen (Minghetti, 2004). However, much remains to be done to completely understand the functioning of COX-3. Both COX2 and COX-1 are sources of pro-inflammatory prostanoids (Smyth et al., 2009); however, new evidence is fast emerging that also points to their role in resolution of inflammation (Williams et al., 1999; Fukunaga et al., 2005; Maskrey et al., 2011). Resolution is a complex process that kicks in once a sufficient inflammatory response has been mounted at the site of inflammation and is triggered by many cellular and molecular cues, such as macrophagic ingestion of apoptotic neutrophils (Ortega-Gómez et al., 2013).

\section{MAMMALIAN/MECHANISTIC TARGET OF RAPAMYCIN (MTOR)}

Rapamycin is a bacterial compound with anti-fungal, anti-cancer, and immunosuppressive properties, and thus, its target molecule, mTOR (mammalian/mechanistic target of rapamycin) has been implicated in processes such as aging, autophagy, and immune responses (Iglesias-Bartolome et al., 2012; Saxton and Sabatini, 2017) along with cellular pathways of proliferation, transcription, and translation (Shafei et al., 2017). The mTOR protein forms two complexes called mTORC1 and mTORC2, with a set of adaptor proteins. mTORC1 and mTORC2 are involved in different regulatory pathways and have different functions. The upstream regulatory components of mTOR include AMPactivated protein kinase (AMPK), glycogen synthase kinase (GSK3), insulin/insulin-like growth factor 1 (IGF-1), and phosphoinositide 3-kinase (PI3-K)/protein kinase B (Akt) while some of the major downstream regulators are $4 \mathrm{E}$-binding proteins (4EBPs) and ribosomal protein S kinase (S6K) (Mueed et al., 2019; Papadopoli et al., 2019).

\section{COX AND ALZHEIMER'S DISEASE}

A lot of work has especially been dedicated to studying the role of COX-2 in neuroinflammatory and neurodegenerative conditions as its overexpression has been related to some of these pathologies (Minghetti, 2004). One of the prime targets of PGs includes the central and peripheral nervous system. The expression of COX-2 in certain types of mammalian neurons is "dynamically regulated" (Minghetti, 2004) by the synaptic activity of these neurons. Many in vitro as well as animal model studies have implicated the role of COX-2 in normal synaptic activity and plasticity (Hölscher, 1995; Kaufmann et al., 1997; Bazan, 2003), yet mice that had been genetically manipulated to knockout COX-2 gene exhibited a more or less normally functioning brain. However, in all these cases, accurate behavioral studies could not be performed as the mice suffered from renal failure very early in their lifespan (Dinchuk et al., 1995; Minghetti, 2004).

Alzheimer's disease $(\mathrm{AD})$ is a progressive neurodegenerative disease and one of the most prevalent types of dementia 


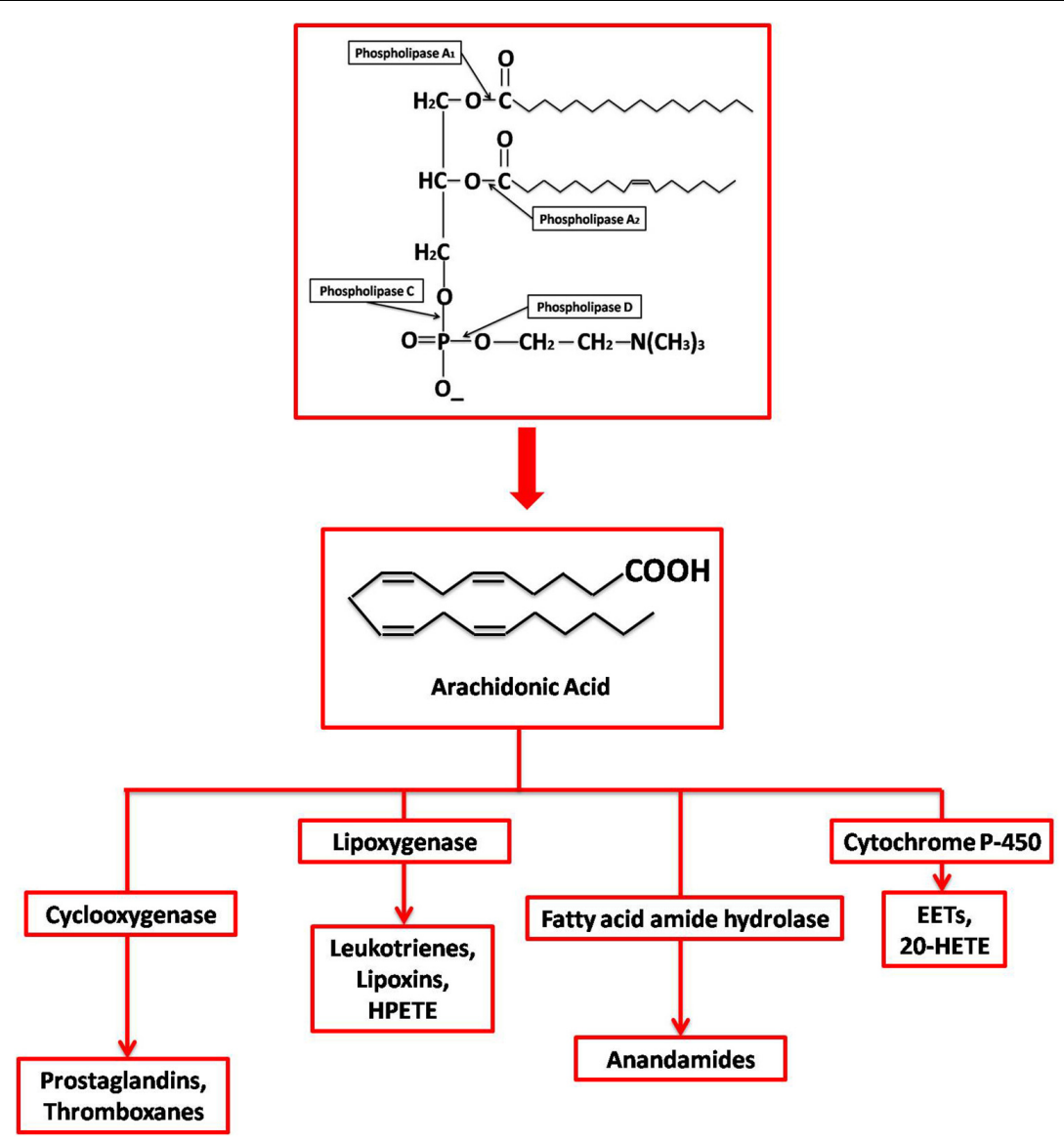

FIGURE 1 | Synthesis and metabolization of Arachidonic Acid. Different phospholipases act at different sites on membrane phospholipids generating various products, including free AA by PLA2. AA is then enzymatically metabolized by (1) Cyclooxygenases into prostaglandins; (2) Lipoxygenases into leukotrienes, lipoxins, and 8- 12- 15-hydroperoxyeicosatetraenoic acid (HPETE); (3) Cyctochrome P450 into epoxyeicosatrienoic acid (EET) and 20-hydroxyeicosatetraenoic acid (20-HETE); and (4) Fatty acid amide hydrolase into endocannabinoid and anadamide.

worldwide (Mueed et al., 2019). It is pathologically marked by the presence of two specific types of deposits in the brain: $\beta$-amyloid plaques and neurofibrillary tangles (NFTs), leading to neuroinflammation, synaptic dysfunction, and eventually neurodegeneration. NFTs are mainly composed of hyperphosphorylated tau (a microtubule associated protein) (Grundke-Iqbal et al., 1986; Alonso et al., 2001) while $\beta$ amyloid plaques are formed due to self-aggregation of the hydrophobic $A \beta$ peptide produced upon cleavage of amyloid precursor protein (APP) (Luo et al., 2016; Mueed et al., 2019). The neuronal autophagy-lysosomal system is affected in $\mathrm{AD}$ pathology and results in low clearance of misfolded and damaged proteins, leading to aggregate formation (Shacka et al., 2008).

Epidemiological studies conducted on $\mathrm{AD}$ showed that populations which had a long history of NSAID use, were at a lower risk of AD (Breitner, 1996; Aisen, 2002; Minghetti, 2004; Hoozemans et al., 2008). This, along with other studies showing associations between COX-2 induction and neurodegeneration (Miettinen et al., 1997) as well as brain parenchymal amyloid plaque formation (Stewart et al., 1997), sparked interest, and subsequent research on potential effects of the COX enzymes and their various pathways in AD progression as NSAIDs are known inhibitors of COX.

Additionally, it has also been shown that lipids and PGs play vital roles in AD (Bazan et al., 2002; Thomas et al., 2016). AA, which gives rise to PGs, also happens to be the second most abundant polyunsaturated fatty acid in the brain (Thomas et al., 2016). It was also found that free AA affects synaptic functions of the brain (Latham et al., 2007). Thus, the levels of free AA in the brain cells, along with a balance between enzymes converting it to other molecules like PGs and enzymes releasing free AA, is also an important factor in AD (Thomas et al., 2016). In spite of this buzz about involvement of $\mathrm{COX}$ in $\mathrm{AD}$, clinical studies carried out with NSAIDs and selective COX-2 inhibitors did not show any significant effects in treatment of AD (Hoozemans et al., 2008). Thus, it can be inferred that the effects of COX enzymes are not as straightforward in the case of $\mathrm{AD}$ as previously thought and the exact mechanisms by which they influence AD progression are not yet known.

The amyloid plaques, a classical hallmark of $\mathrm{AD}$, are associated with pro-inflammatory cells and proteins. These proteins are found in the brain throughout the various stages of $\mathrm{AD}$ 
progression (Hoozemans et al., 2008). It is also speculated that inflammatory molecules may have dual role in $\mathrm{AD}$ as they exert both beneficial as well as detrimental effects based on their concentration and the stage of $\mathrm{AD}$ in which they are being expressed (Hoozemans et al., 2008). Along with this, epidemiological and genetic evidence also exist which points to the fact that inflammation is one of the key processes contributing to $\mathrm{AD}$. However, due to failure of NSAIDs and selective COX-2 inhibitors against $\mathrm{AD}$, alternate views are being considered which think of these drugs to perhaps have a preventive role with respect to $\mathrm{AD}$ and inflammation as merely a secondary phenomenon to clear off debris generated from more central underlying processes of AD (Wyss-Coray and Mucke, 2002; Hoozemans et al., 2006). It has also been reported that COX-2 expression in $\mathrm{AD}$ brains is correlated with altered expression of cell cycle proteins (Hoozemans et al., 2008). It was found that cell proliferation, adhesion, and differentiation genes were some of the most commonly upregulated ones along with PG synthesis genes in AD brains (Blalock et al., 2004).

COX-2 is constitutively expressed in certain cell populations of the brain, and additionally it is induced by inflammatory molecules such as cytokines, IL-1, IL-2, and TNF- $\alpha$ (Hoozemans et al., 2008). But, it is expressed in microglia (the local macrophages of the brain) only under very specific conditions, such as in chronic cases of cerebral ischemia (Tomimoto et al., 2000; Walsh et al., 2000). The expression of COX-2 is also absent in astrocytes (Pasinetti and Aisen, 1998; Hoozemans et al., 2001). COX-2 expresses differentially in different stages of AD and has pleiotropic functions in the brain (Hoozemans et al., 2008). In the early stages of the disease, COX-2 expression is increased (Ho et al., 2001; Hoozemans et al., 2001, 2002) and it is primarily expressed in pyramidal neurons (Braak and Braak, 1991). IL-1 levels also go up in AD due to association of neuritic plaques with microglial cells that express IL-1 (BlumDegena et al., 1995). It is then reasonable to think that these IL-1 molecules perhaps induce higher expressions of COX-2. The expression of COX-2 has also been linked to cell cycle control (Xiang et al., 2002; Wu Chen et al., 2004), which may be involved in (re)generative pathways. However, these reasons are still controversial as the elevated expressions of COX-2 occur before the activation of microglia and astrocytes as shown by neuropathological studies (Hoozemans et al., 2002), whereas the expression has been found to reduce later on as the disease progresses and the number of neurons expressing COX-2 in severe cases of $\mathrm{AD}$ is very few (Hoozemans et al., 2004), which might be due to selective degeneration of neurons at these stages and a loss in the synaptic activity (Hoozemans et al., 2008).

It has even been observed that NSAIDs affected molecules and pathways involved in $\mathrm{AD}$ other than $\mathrm{COX}$; for example peroxisome proliferator activated receptor $\gamma(\operatorname{PPAR} \gamma)$ is found to be up-regulated in $\mathrm{AD}$ and can be activated by NSAIDs (Kitamura et al., 1999). Activation of PPAR $\gamma$ leads to clearance of $\mathrm{A} \beta$ deposits in neuronal as well as non-neuronal cells (Camacho et al., 2004). NSAIDs have also been found to lower $A \beta$ deposits by targeting the $\gamma$-secretase enzyme and inhibition of nuclear

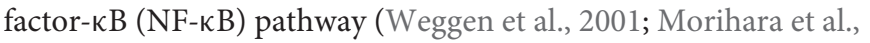
2002; Eriksen et al., 2003).

\section{ROLE OF MTOR IN AD}

Recently, mTOR has also been found to be associated with AD pathology. Since AD is an age-associated disease, classical signs of aging like loss of proteostasis, mitochondrial dysfunction, altered intercellular communication, etc. can also be associated with mTOR (López-otín et al., 2013; Papadopoli et al., 2019). Since mTOR hinders autophagy, it promotes $A \beta$ deposition in brain (Uddin et al., 2018). Due to disruption of the autophagiclysosomal pathway, immature autophagolysosomes give rise to autophagic vacuoles that are then populated by $\beta$-amyloid plaques (Mueed et al., 2019). Rapamycin, however, is known to lessen these numbers (Haung Yu et al., 2005). Normally, adults contain very few autophagic vacuoles in their neurons (Cuervo et al., 2005) while these go up significantly in the affected regions of an $\mathrm{AD}$ brain (Haung Yu et al., 2005). An opposite connection has also been reported where induction with $\mathrm{A} \beta$ activates mTOR and its regulatory components (Bhaskar et al., 2009). Studies in both mouse models and humans have shown that the mTOR pathway is hyperactivated in AD (Perluigi et al., 2015). However, it has also been suggested that different neurons in an $\mathrm{AD}$ brain may have either upregulated or downregulated signaling cascades of mTOR based on how they react to $\mathrm{AD}$ stresses (Pei and Hugon, 2008).

Protein misfolding and subsequent aggregation is at the heart of Alzheimer's pathophysiology (Mueed et al., 2019). The mTORC1 complex has been reported to stimulate protein synthesis (Papadopoli et al., 2019). However, there have been contradicting reports in case of regulation of proteolysis, with some claims of mTOR suppressing protein degradation (Zhao et al., 2015; Rousseau and Bertolotti, 2016) and others of mTOR enhancing it (Papadopoli et al., 2019). Thus, mTOR can play a role in the aberrant proteostasis in AD patients. Tau is one of the proteins whose translational pathway involves mTORdependent signaling via a 5'top mRNA (Pei and Hugon, 2008). Thus, upregulated and continuous production of tau proteins in degenerating neurons is regulated by mTOR signaling via the P70S6K and 4EBP1 pathways (Pei et al., 2008).

Moreover, mTOR mediates tau synthesis and phosphorylation at specific sites and is found to co-localize with NFTs (An et al., 2003; Tang et al., 2013). This results in microtubule instability as tau is an essential microtubule associated protein and its hyperphosphorylation causes it to detach from microtubules (Mueed et al., 2019).

\section{COX-2 AND MTOR IN CELL METABOLISM AND SIGNALING CASCADES: IMPLICATIONS IN AD}

Small metabolites are known to be able to cross the blood-brain barrier and are also affected by environmental and genetic cues. Aberrant levels of amino acids, lipids, certain neurotransmitters, 
and other metabolites are found in both blood and brain in mouse models of AD (Pan et al., 2016). Many phospholipids have also been demonstrated to contribute to $\mathrm{AD}$ occurrence and progression (Li D. et al., 2016). Additionally, a general loss of protein homeostasis and glucose metabolism are characteristic of AD (Papadopoli et al., 2019).

Along with growth factors, cellular energy levels, and oxygen levels, mTOR is also involved in sensing nutrients like amino acids and integrating these multitude of signals to produce a response according to the cell's need to further grow or differentiate (Figure 2; Howie et al., 2014; Goberdhan et al., 2016). Two models have been suggested to describe amino acid sensing by mTORC1 and the subsequent effector responses: a single hub, comprising of a single mTORC1 collecting all the micro-environmental cues to produce a variety of outputs; and a multi-hub model, where two different mTORC1 function in different parts of the cell (Jewell et al., 2015; Fan et al., 2016; Goberdhan et al., 2016). Many amino acid transporters, such as members of the proton-assisted transporters (PATs) family, are localized on the late endosomal and lysosomal (LEL) surfaces (Goberdhan et al., 2005; Goberdhan, 2010; Figure 2). Apart from the LELs, other possible amino acid sensing locations via mTORC1 have also been suggested such as the Golgi complex, supporting the multi-hub model of sensing. The entire process of amino acid sensing by mTORC1 has been divided into a priming step (sensitization of mTORC1 for the final activation) and an actual activation step. L-Glutamine, L-glycine, L-glutamic acid, L-serine, and L-arginine are some of the amino acids involved in priming whereas activation is majorly carried out by L-leucine and to some extent by L-methionine, L-isoleucine, and L-valine. L-Cysteine mostly impedes the priming step. Some of these amino acids (leucine, glutamine, serine, and arginine) are known to aid in autophagy inhibition by activating mTORC1 (Shafei et al., 2017). As previously mentioned, autophagy dysfunction is a key player in AD development (Saxton and Sabatini, 2017). Moreover, amino acids as well as enzymes metabolizing them in $\mathrm{AD}$ patients are also known to deter from their normal levels (Shafei et al., 2017). Lower levels of branched chain amino acids like valine, especially in later stages of life, have been associated with a higher risk of AD (Tynkkynen et al., 2018). Cysteine has also been directly linked to $\mathrm{AD}$ and other neurodegenerative diseases as plasma levels of $\mathrm{AD}$ patients were found to have higher cysteine and sulfate ratio early in the morning. Higher cysteine implies higher thiol concentration in the cell, which could hinder with the functioning, confirmation, and synthesis of protein (Heafield et al., 1990). Glutamate is also known to regulate mTORC1via glutamate dehydrogenase $(\mathrm{GDH})$ and human branched chain aminotransferase (hBCAT) enzymes. Interestingly, glutamate, which is a neurotransmitter involved in excitatory functions, has also been found to be toxic and damaging to neurons when present in higher concentrations (Schubert and Piasecki, 2001).

Analogous to amino acid sensing, mTORC1 is also involved in nucleotide sensing in a cell (Hoxhaj et al., 2017). As mTORC1 promotes ribosome biogenesis, $60 \%$ of which consists of rRNA, it was found to boost de novo nucleotide (both purine and pyrimidine) synthesis (Ben-Sahra et al., 2013; Figure 2). The pathway for de novo pyrimidine synthesis has been reported in an adult human brain, but whether or not mTORC1 has any role to play in it is not yet known. Moreover, the expression levels of several genes involved in synthesis of mRNAs (such as dihydroorotate dehydrogenase and uridine-cytidine kinase 2) for both the de novo as well as salvage pathways were found to be modified in case of AD patients (Pesini et al., 2019). The depletion of purines, specifically adenylates, was found to inhibit mTORC1 via the GTPase-activating protein (GAP) activity of TSC (Tuberous sclerosis complex) (Hoxhaj et al., 2017). The same study also reported mTORC1 inhibition on longer periods of guanylate-depletion due to degradation of Rheb. The TSC complex helps in maintaining Rheb in a GDP-bound state thereby inhibiting mTORC1 (Dibble et al., 2012). However, mTORC1 is also reported to be inhibited by guanylate depletion due to binding of Rheb-GTP and farnesylation (Emmanuel et al., 2017; Figure 2). Supplementation of uridine and other nutrients has positive effects in AD therapy (Engelborghs et al., 2014). In fact, uridine is also a part of the recipe for a rather popular medical supplement called Souvenaid ${ }^{\circledR}$, known to support synaptic generation and function as a part of AD therapy (Ritchie et al., 2014).

The nutrient microenvironment inside a cell and sensing by mTOR is also closely related to $\mathrm{T}$ cell regulation, activation, and differentiation. While mTOR activation is needed for effector $\mathrm{T}$ cell proliferation and differentiation, it inhibits FOXP3 expression, the master transcription factor for regulatory $\mathrm{T}$ cells (Sauer et al., 2008; Delgoffe et al., 2010). Regulatory T cells are reported to be upregulated in an $\mathrm{AD}$ patient's blood (Sommer et al., 2017). It was also shown that mTORC1 promotes selective Th1 differentiation while mTORC2 Th2 differentiation (Lee et al., 2010). The potential role of adaptive immune cells in AD, however, is still unclear with reports of both an enhanced proand anti-inflammatory response (Sommer et al., 2017; Figure 2).

The COX-2/PG axis, in addition to its role in tissue inflammation, also mediates insulin secretion in adipose tissue and differentiation of adipocytes (Fjaere et al., 2014). Epidemiological studies have linked diabetes and obesity with dementia (Ferreira et al., 2018). In fact, a lot of recent studies have highlighted the common cellular pathways underlying both diabetes and $\mathrm{AD}$, thereby coining the term "type-3-diabetes" or "brain diabetes" to refer to AD (Xu et al., 2019). Anti-diabetic drugs are being explored as potential candidates of anti-AD therapy (De Felice, 2013). PGs have been reported to exert both pro- as well as anti-obesogenic effects (Madsen et al., 2008). Beige adipocytes play important roles in counteracting obesity and other related disorders like diabetes and cardiovascular diseases (Boström et al., 2012; Harms and Seale, 2013; Cohen et al., 2014; X. Zhang et al., 2018). The inter-communications between adipose tissue and CNS puts obese people at a higher risk of developing cognitive and other mental disorders (Forny-Germano et al., 2019). Interestingly, mTORC1 is also hyperactivated in adipose tissues of obese rodents and its enhanced expression in fact gives rise to adiposity as well as obesity (Um et al., 2004; Khamzina et al., 2005; Polak et al., 2008; Laplante and Sabatini, 2012). Most groups have reported 


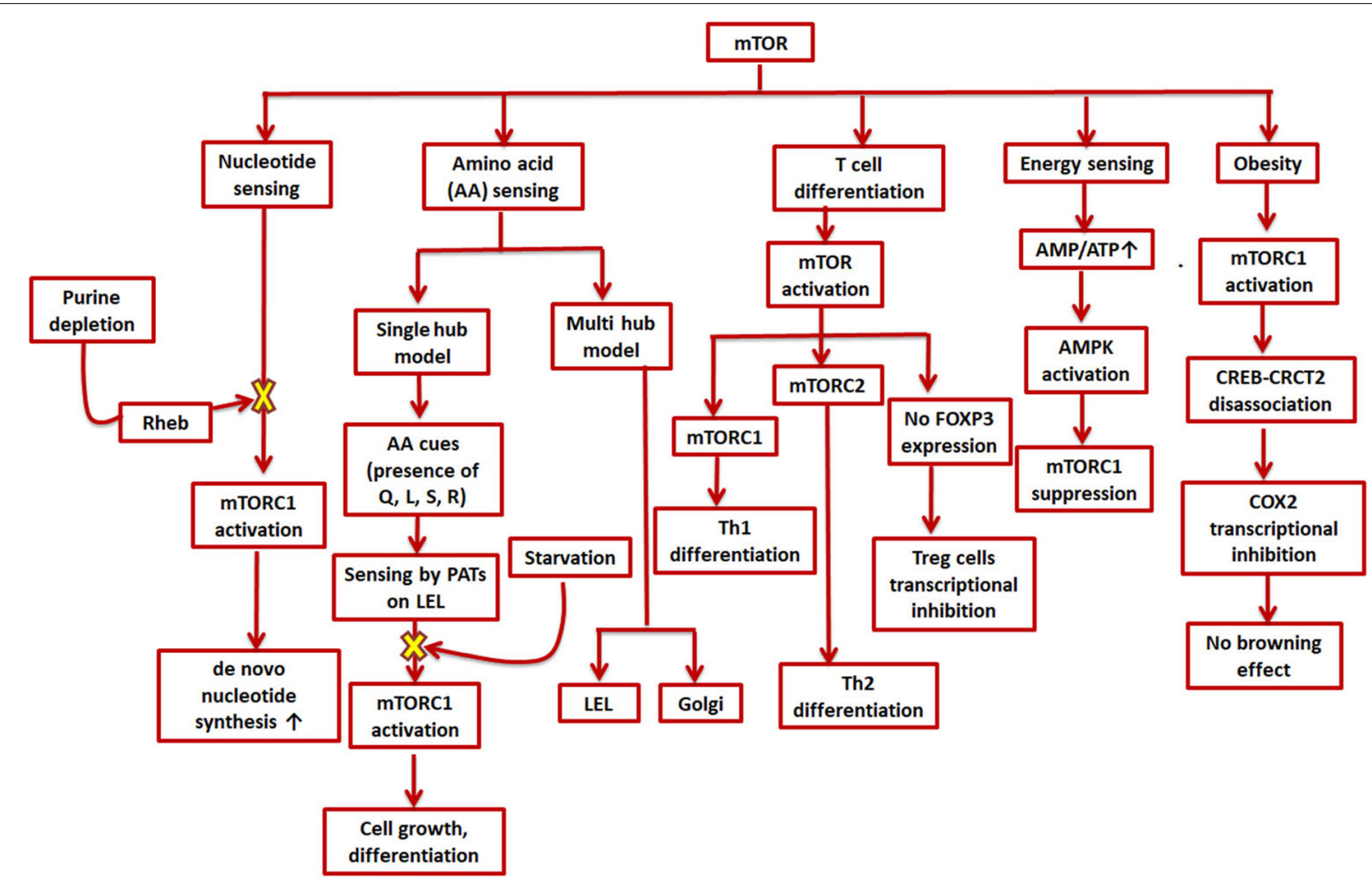

FIGURE 2 | Role of mTOR in cell metabolism and signaling cascades. mTOR is involved in various environmental sensing and growth-related processes in the cell. mTORC1 stimulates de novo synthesis of nucleotides as well as responds to amino acid availability by promoting cell growth and differentiation; mTOR furthers helper T-cell differentiation while impeding regulatory T-cell differentiation; a higher AMP/ATP ratio can suppress mTORC1 and thus inhibit energy expending processes; and mTORC1 inhibits transcription of COX-2 which promotes obesity.

that mTORC1 is inhibitory for thermogenesis and "browning effect" (conversion of white adipose tissue to brown/beige adipocytes), which help tackle obesity by inducing enhanced energy consumption processes (M. Um et al., 2004; Polak et al., 2008; Liu et al., 2014; Wada et al., 2016). Nevertheless, there have been a few studies which have shown that inactivation of mTORC1 also compromises thermogenesis (D. Liu et al., 2016; Tran et al., 2016). While exposure to cold is also known to induce browning effect in mammals, it has been found to modify pathways involved in $\mathrm{AD}$ in a study carried out in mice models (Xu et al., 2019). Since mTOR and COX-2 have been found to operate together directly or indirectly in various other disorders or conditions, it can also be speculated that they may affect each other in this particular case. In one such study, mTORC1 inactivation in the mice adipose tissue causes COX-2/PG pathway induction, sending off a paracrine signal to initiate browning effect (Zhang et al., 2018), whereas when mTORC1 is activated, it phosphorylates a serine residue ( $\operatorname{Ser}^{136}$ ) in CREB-regulated transcription coactivator 2, preventing its efficient association with CREB and subsequently CREB binding with COX-2 promoter (Zhang et al., 2018). As CREB binding enhances COX-2 promoter activation (Reddy et al., 2000; Yang and Bleich, 2004), mTORC1 activation eventually leads to transcriptional inhibition of COX-2, thereby preventing beige adipogenesis (Figure 2).

\section{COX-2 AND MTOR IN OSMOPROTECTION}

For normal cell functioning it is essential that the cellular volume, electrolytes, and other solute concentrations be maintained. Changes in the extracellular tonicity results in accompanying changes in the intracellular environment to ensure the cell maintains its normal volume (Macknight, 1988). The kidneys are one of those mammalian organs wherein cells are subjected to extreme concentrations of solutes like urea and $\mathrm{NaCl}$ (Burg et al., 2007). However, many diseases are known to be caused by the hyperosmotic stresses faced by non-renal tissues (Brocker et al., 2012). Cells deal with these conditions using certain small organic molecules, called osmolytes, that are dissolved in the cellular as well as extracellular fluids (Wijayasinghe et al., 2017). These organic osmolytes have been found to be accumulated in the renal medullary cells in situations of osmotic stress (Wijayasinghe et al., 2017). COX-2 and mTOR are involved in different kinds of osmoprotective pathways in different cell types (Figure 3). 


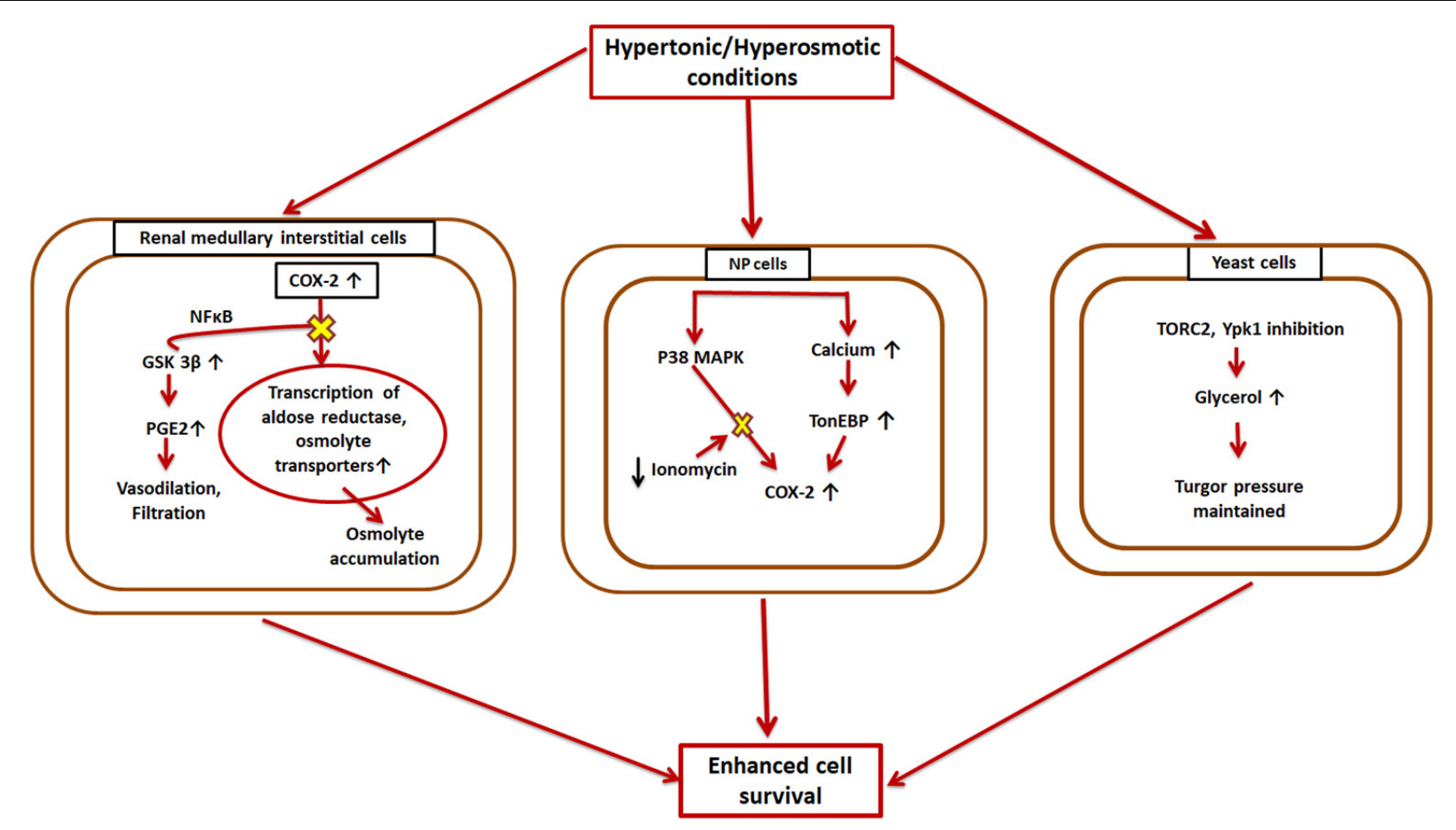

FIGURE 3 | Hyperosmotic induction of COX-2 and mTOR. COX-2 is overexpressed in the reno-medullary interstitial cells in a hyperosmotic environment. This leads to higher transcriptional rates of osmolyte transporters, and thus the cell can accumulate large amounts of osmolytes to aid in its survival, while GSK-3 $\beta$ opposes this pathway; Nucleus pulposus (NP) cells also cope with hypertonic conditions by overexpressing COX-2 via two different cascades-TonEBP and MAPK; Yeast cells exhibit higher levels of TORC2 under hypertonic conditions resulting in higher glycerol concentrations which eventually reestablishes cell turgor pressure.

Both COX-1 and COX-2 are expressed in different parts of the kidney (Y. Harris et al., 1994; Guan et al., 1997) with different regulatory mechanisms. While COX-2 exhibits expression based on the surrounding tonicity, COX-1 does not follow any such pattern (Briggs, 1999). Thus, there were speculations that COX-2 might have an osmoprotective function in the kidneys. Treatment with NSAIDs and COX-2 specific inhibitors in the renomedullary interstitial (RMI) cells reduces osmolyte accumulation induced by hypertonic conditions in these cells and affects their survival (Moeckel et al., 2003). It was found that COX-2 causes this effect by transcriptional regulation of osmolyte transporters. Later on, it was also shown that GSK-3 $\beta$ kinase is a key player in this process and affects COX-2 via a signaling pathway involving NF- $\kappa$ B (Rao et al., 2004). The increased hypertonic conditions upregulate GSK-3 $\beta$ activity in the RMI cells, which increases their apoptotic rate (Rao et al., 2004). Thus, GSK-3 $\beta$ works as an antagonist of COX-2. TonEBP/NFAT5, a master transcription factor of osmoprotective genes (Favale et al., 2007), has also been found to enhance COX-2 mRNA levels in osmotically stressed RMI cells (Favale et al., 2009). MAPK family members and Src kinases are other known enzymes that are implicated in hypertonicity-induced COX-2 regulation (Burg et al., 2007; Yang et al., 2000; Figure 3).

Another part of the body that experiences higher and a constantly changing osmolarity is the inner core of vertebral disc, called nucleus pulposus (NP) (Choi et al., 2018). Therefore, the NP cells have mechanisms to adapt to these hyperosmotic microenvironments, which involve up-regulation of COX-2. This upregulation is intracellular calcium-dependent, but rather than the calceneurin signaling pathway, it occurs through TonEBP (Choi et al., 2018). It was found that TonEBP overexpression resulted in enhanced COX-2 promoter activity while its silencing resulted in diminished COX-2 promoter activity (Choi et al., 2018). TonEBP silencing also causes COX-2 enzyme levels to fall in iso-osmotic conditions (Choi et al., 2018). Additionally, p38 MAPK pathway also induced elevated expression of COX-2 under hyperosmotic conditions in NP cells. However, ionomycin treatment nullified this effect (Choi et al., 2018). This COX2 overexpression eventually aids in (NP) cell survival under osmotic stress (Figure 3).

Additionally, in case of yeasts, mTORC2 (referred to as TORC2 in this case) has been demonstrated to be involved in osmotic-homeostasis maintenance (Eltschinger and Loewith, 2016; Figure 3). Ypk1 and Ypk2, homologs of Akt, are two important downstream substrates of TORC2. Hypertonic conditions inhibit TORC2 and Ypk1, which eventually results in increased glycerol concentrations in the cell and reestablishes the turgor pressure.

Osmolytes are reported to play corrective roles in many human pathologies caused by protein misfolding, although nothing specifically for AD (Kim et al., 2006). Meanwhile, a typical AD brain is marked by misfolded proteins that keep 
getting accumulated and result in autophagic and lysosomal dysfunction as well as amyloid and tau aggregate formation (Efeyan et al., 2013). In fact, hypertonicity is one of the many causes of protein damage in cells (Hahr, 2015).

\section{COX-2 MODULATION OF mTOR}

Both COX-2 and mTOR have been extensively studied individually and in combination with other speculated regulators of $\mathrm{AD}$ in the disease's progression (Hoozemans et al., 2008; Pei and Hugon, 2008; Tang et al., 2015; Thomas et al., 2016; Mueed et al., 2019). The exact role COX-2 plays in the various stages of the disease is still debated, with reports claiming both beneficial as well as detrimental effects of the enzyme in the various $\mathrm{AD}$ associated pathologies (Minghetti, 2004; Hoozemans et al., 2008). However, mTOR is mostly known to be hyperactivated in $\mathrm{AD}$ and causes excessive phosphorylation of tau protein and formation of $\mathrm{A} \beta$ plaques and NFTs (Figure 4). Both have been implicated in development of synaptic plasticity under physiological conditions (Minghetti, 2004; Papadopoli et al., 2019). Interconnected signaling and working of COX-2 and mTOR has been the subject of many studies in the case of various types of cancer (Chuang et al., 2019(H. Lipskar et al., 2009; Rouzer and Marnett, 2009; Li H. et al., 2016), but no such studies have yet been conducted for AD. Both cancer and $\mathrm{AD}$ have a faulty DNA damage repair mechanism at their core that causes uninhibited growth and neuronal loss, respectively (Behrens et al., 2009). Rapamycin has been found to exert anti-tumor and anti-angiogenic effects by inhibiting neovascularization (Guba et al., 2002; Phung et al., 2006). It can do this via either an mTOR-dependent or independent pathway. In case of the mTOR-independent pathway, the phosphorylation of downstream effectors of mTOR remains unchanged and other molecules including COX-2 are instead involved (Jung et al., 2003; Lipskar et al., 2009). Moreover, cancer and AD have been shown to manifest an inverse relationship via many cellular pathways and signaling molecules such as p53 and cAMP and hormones like estrogen, growth factors, neutrophins, etc (Shafi, 2016).

In yet another study carried out on endometrial cancer (EMC) on mouse models and human cell lines, it was established that both COX-2 and mTORC1 work cooperatively to reduce tumor load and exacerbate the cancer. This common signaling pathway also involved Akt as both COX-2 and mTORC1 are downstream targets of Akt (Gadducci et al., 2008; Jae et al., 2009; Slomovitz and Coleman, 2012; Figure 4). Although these studies have been limited to mostly cancer models, similar pathways could exist in case of $\mathrm{AD}$ as well. If the presence of such a connection between COX-2 and mTOR could be established in AD, it could be exploited as a therapeutic strategy.

As mentioned in previous sections, mTOR controls T-cell activation and innate immune responses. mTOR is also known to modulate COX-2 expression in immune reactions. An in vitro study conducted on enhancement of immunomodulatory effects of human bone marrow mesenchymal stem cells showed elevated levels of COX-2 and higher phosphorylation of kinases, GSK-3b, and Akt, upon mTOR inhibition by short-term $(4 \mathrm{~h})$ rapamycin treatment (Wang et al., 2017; Figure 4). However, COX-2 is significantly downregulated on longer rapamycin treatments. PGE2, which plays important roles in immunosuppression by inhibition of NK (natural killer) cell cytotoxicity, dendritic cell maturation, and T cell proliferation (Spaggiari et al., 2008; Wang et al., 2017), was also found to be upregulated (Figure 4). Apart from COX-2 being overexpressed during inflammatory reactions including $\mathrm{AD}$ and cancers, it is also known to resist apoptosis (Tsujii and DuBois, 1995). Similar to COX-2, mTOR is also thought to be involved in apoptosis and activation of cell cycle in post mitotic neurons (Pei and Hugon, 2008; Figure 4). Thus, NSAIDs and selective COX-2 inhibitors induce apoptosis. Two pathways have been suggested for this: stimulation of ceramide (a death signal) production by availability of higher amounts of AA (Chan et al., 1998), and downregulation of Bcl-2 (X. Liu et al., 1998; Sheng et al., 1998). Alternatively, a selective COX-2 inhibitor, celecoxib, is thought to induce apoptosis by selectively blocking Akt pathway (Hsu et al., 2000). However, the mechanism behind this remains elusive as celecoxib does not significantly affect the major kinase, PI-3K, or the phosphatase, protein phosphatase $2 \mathrm{~A}$, involved in the activation of Akt (Hsu et al., 2000). Interestingly, this might indicate another possible pathway by which COX-2 modulates mTOR signaling as Akt is one of the major upstream regulators of mTOR.

\section{COX-2 AND mTOR-BASED THERAPIES}

As discussed earlier, NSAIDs were found to be associated with a lower vulnerability to $\mathrm{AD}$ due to lowering levels of $\mathrm{A} \beta 42$ as well as reducing inflammation. A lot of studies have been conducted in this regard exploring different aspects of the disease development and progression. Various therapeutic approaches for $\mathrm{AD}$ have also been reviewed previously (Mueed et al., 2019).

It was found that selective COX-2 inhibitors could restore long term potentiating which was lost due to incubation with external $A \beta 42$ in studies carried out in rat hippocampal slices, while inhibition of only COX-1 failed to produce any such effects (Kotilinek et al., 2008). The same study also reported regarding restoration of memory in Tg2576 mice over-expressing APP by both selective COX-2 inhibitors as well as non-selective NSAIDs. However, these beneficial effects of COX-2 inhibition were lost on addition of exogenous PGE2 but not by inflammatory cytokines like IL- $1 \beta$, TNF- $\alpha$, or even A $\beta$. Thus, the authors proposed an alternative mechanism of NSAID action on AD: preventing PGE2 response at synapses due to blockage of COX-2.

As previously stated, mTOR is known to be hyperactivated in an $\mathrm{AD}$ brain and exerts its effects by affecting key cellular processes such as nucleotide synthesis, protein synthesis, and modifications, mitochondrial dynamics, lipid metabolism and the cellular autophagic system. Therapies against AD and other neurodegenerative disorders have thus also targeted mTOR. Inhibition of mTOR using rapamycin and its analogs has shown reduction in the amounts of amyloid and tau deposits in early stage-AD-affected brains of mice and improved their cognitive abilities (Spilman et al., 2010; Majumder et al., 2011). 


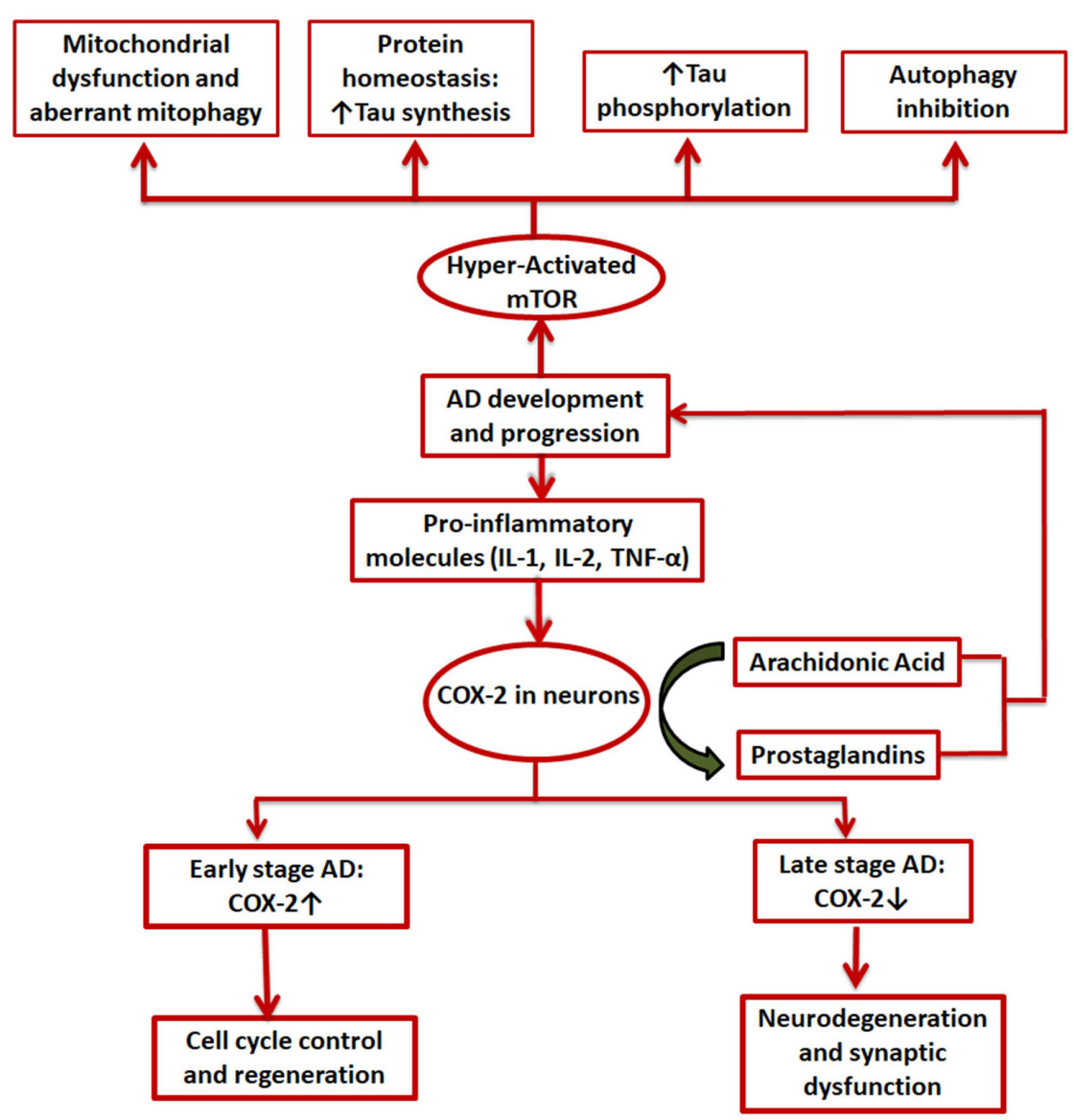

FIGURE 4 | Involvement of COX-2 and mTOR in AD. Pro-inflammatory molecules induce COX-2 expression in certain brain cells. It is upregulated in the initial stages of $A D$ and is expected to be involved in cell cycle control and regenerative pathways while in the later stages a decline in COX-2 levels is seen, mainly due to degeneration of neurons by the disease; mTOR, on the other hand, is always hyperactivated in case of AD and exerts its effects in mainly 4 ways: mitochondrial dysfunction, aberrant proteostasis, tau hyperphosphorylation, and inhibition of autophagy.

In fact, humans who were administered with a rapamycin analog, everolimus, in order to elicit immunosuppression after a heart transplant also showed better memory skills than the control group (Papadopoli et al., 2019). mTOR overexpression has been routinely linked to intracellular tau accumulation and translocation. Its inhibition via rapamycin or silencing by mutation leads to lower tau levels in the cell (Tang et al., 2015). This has implications across various tauopathies and presents a potential therapeutic approach. mTOR inactivation has proved to be helpful in reducing microglial-inflammatory responses in the brain. Some of these studies have also shown a possible COX involvement in the process as rapamycin treated microglia also resulted in lower levels of COX-2 (Dello Russo et al., 2013).

COX-2 is also implicated in a variety of cancers (Hwang et al., 1998; Pandey et al., 2008; Greenhough et al., 2009; Alexanian et al., 2014; Mattsson et al., 2015) and its inhibition can also be used as one of the ways for cancer therapy. Tuberous sclerosis complex (TSC) caused as a result of mutations in any of the two tumor suppressor genes, TSC1 and TSC2, leads to formation of localized tumor masses in multiple organs (Borkowska et al., 2011; Kwiatkowski and Manning, 2014; Schepis, 2016). mTORC1 is known to be hyperactivated by loss of TSC2 in TSC tumors (Moavero et al., 2015; Li H. et al., 2016). This leads to downregulation of COX-2 activity via activation of STAT3 (signal transducer and activator of transcription 3). It was also found that IL-6 is a downstream target of COX-2 in cells with loss-of-Tsc2 mutation and thus reduced activity of COX-2 inhibits IL- 6 which limits cellular proliferation ( $\mathrm{Li} \mathrm{H}$. et al., 2016). Rapamycin and celecoxib, together, were found to be most useful against TSC in Tsc2 negative cells, than either individually (Li H. et al., 2016).

\section{CONCLUSION AND FUTURE PERSPECTIVES}

COX-2 is involved in diverse cellular functions in the human body such as PG synthesis, insulin secretion, adipogenesis, CNS autonomic regulation, etc., and thus, any structural or functional aberrations in the enzyme will have varied repercussions across many pathways. Many inflammatory and neoplastic disorders are related to COX-2 expression levels and activity. Similarly, mTOR affects central cellular activities such as growth, 
transcription, and translation. It has also been found to play a vital role in inflammatory and age-related diseases. COX2 and mTOR operate in a number of overlapping pathways such as nutrient sensing, obesity, apoptosis, immune reactions, osmoprotection, etc.

Alzheimer's is one of the world's leading types of dementia and a neuro-inflammatory disease. COX-2 has been classically implicated in $\mathrm{AD}$ and much research has been done to develop therapies against $\mathrm{AD}$ based on blocking or deleting COX-2. However, it has been known for some time now that neither the cause of $\mathrm{AD}$ nor the role COX-2 plays in its occurrence and progression is as it was traditionally considered. There have been many views rejecting the amyloid as well as tau hypotheses to be at the heart of AD. Also, COX-2 is now thought to have pleiotropic effects in the brain and AD pathophysiology as the enzyme exhibits different expression levels during different stages of the disease with elevated levels in the early stages and a gradual fall later on. Moreover, other molecular targets of NSAIDs rather than the COX enzymes are being considered as possible key players in AD. Thus, in order to effectively tackle $\mathrm{AD}$, it has to be considered in its entirety and not as isolated underlying pathways.

mTOR entered the $\mathrm{AD}$ picture as a molecule of interest quite recently but it has since been well established in $\mathrm{AD}$ pathology. It is supposedly overexpressed in $\mathrm{AD}$, promotes amyloid- as well as tau-deposition, and is also involved in their targeting to various cell organelles to a certain extent. Inhibition of mTOR in vitro and in vivo models of $\mathrm{AD}$ has demonstrated improved memory and other cognitive abilities which are compromised in the disease.

\section{REFERENCES}

Aisen, P. S. (2002). The potential of anti-inflammatory drugs for the treatment of Alzheimer's disease. Lancet Neurol. 1, 279-284. doi: 10.1016/S1474-4422(02) 00133-3

Alexanian, A., Miller, B., Chesnik, M., Mirza, S., and Sorokin, A. (2014). Post-translational regulation of COX2 activity by FYN in prostate cancer cells. Oncotarget 5, 4232-4243. doi: 10.18632/oncotarget. 1983

Alonso, A. D. C., Zaidi, T., Novak, M., Grundke-Iqbal, I., and Iqbal, K. (2001). Hyperphosphorylation induces self-assembly of tau into tangles of paired helical filaments/straight filaments. Proc. Natl. Acad. Sci. U.S.A. 98, 6923-6928. doi: $10.1073 /$ pnas.121119298

An, W. L., Cowburn, R. F., Li, L., Braak, H., Alafuzoff, I., Iqbal, K., et al. (2003). Up-regulation of phosphorylated/activated p70 S6 kinase and its relationship to neurofibrillary pathology in Alzheimer's disease. Am. J. Pathol. 163, 591-607. doi: 10.1016/S0002-9440(10)63687-5

Balsinde, J., Balboa, M. A., and Dennis, E. A. (1998). Functional coupling between secretory phospholipase A2 and cyclooxygenase- 2 and its regulation by cytosolic group IV phospholipase A2. Proc. Nalt. Acad. Sci. U.S.A. 95, 7951-7956. doi: 10.1073/pnas.95.14.7951

Bazan, N. G. (2003). Synaptic lipid signaling: significance of polyunsaturated fatty acids and platelet-activating factor. J. Lipid Res. 44, 2221-2233. doi: 10.1194/jlr. R300013-JLR200

Bazan, N. G., Colangelo, V., and Lukiw, W. J. (2002). Prostaglandins and other lipid mediators in Alzheimer's disease. Prostag. Oth. Lipid M 68-69, 197-210. doi: 10.1016/S0090-6980(02)00031-X

Behrens, M., Lendon, C., and Roe, C. (2009). A common biological mechanism in cancer and Alzheimers disease? Curr. Alzheimer Res. 6, 196-204. doi: 10.2174/ 156720509788486608
The main aim of this review was to explore the biphasic nature of relationship between COX-2 and mTOR in key cellular processes, some of which have direct roles in $\mathrm{AD}$ progression. This suggests a very strong possibility that their relationship could be exploited in order to develop an effective counter for AD. Moreover, their actions have already been found to be interdependent in the case of a number of cancers, and anti-cancer therapies targeting the two of them are underway. However, dedicated studies in this direction in the case of $\mathrm{AD}$ are still, to the best of our knowledge, non-existent. The possible future prospective in this direction would include exploring in detail selected targets of interest, such as Akt, and all their associated pathways which may provide specific answers as to if and how COX-2 and mTOR co-operate in $\mathrm{AD}$ and if drugs targeting either or both of these would be helpful in combating the disease.

\section{AUTHOR CONTRIBUTIONS}

AT wrote the manuscript. NP made the background of the manuscript and finalized the manuscript. MK gave valuable comments and help in writing the manuscript. All authors contributed to the article and approved the submitted version.

\section{FUNDING}

This work was supported by Enhanced Seed grant EF/201920/QE04-02 to NP from Manipal University Jaipur, Rajasthan, India is gratefully acknowledged.

Ben-Sahra, I., Howell, J. J., Asara, J. M., and Manning, B. D. (2013). Stimulation of de Novo pyrimidine synthesis by growth signaling through mTOR and S6K1. Science 339, 1323-1328. doi: 10.1126/science. 1228792

Bhaskar, K., Miller, M., Chludzinski, A., Herrup, K., Zagorski, M., and Lamb, B. T. (2009). The PI3K-Akt-mTOR pathway regulates a oligomer induced neuronal cell cycle events. Mol. Neurodegener. 4, 1-18. doi: 10.1186/1750-1326-4-14

Bidgood, M. J., Jamal, O. S., Cunningham, A. M., Brooks, P. M., and Scott, K. F. (2000). Type IIA Secretory Phospholipase A 2 Up-Regulates Cyclooxygenase2 and Amplifies Cytokine-Mediated Prostaglandin Production in Human Rheumatoid Synoviocytes. J. Immunol. 165, 2790-2797. doi: 10.4049/jimmunol. 165.5.2790

Blalock, E. M., Geddes, J. W., Chen, K. C., Porter, N. M., Markesbery, W. R., and Landfield, P. W. (2004). Incipient Alzheimer's disease: microarray correlation analyses reveal major transcriptional and tumor suppressor responses. Proc. Natl. Acad. Sci. U.S.A. 101, 2173-2178. doi: 10.1073/pnas.0308512100

Blum-Degena, D., Müller, T., Kuhn, W., Gerlach, M., Przuntek, H., and Riederer, P. (1995). Interleukin-1 $\beta$ and interleukin-6 are elevated in the cerebrospinal fluid of Alzheimer's and de novo Parkinson's disease patients. Neurosci. Lett. 202, 17-20. doi: 10.1016/0304-3940(95)12192-7

Borkowska, J., Schwartz, R. A., Kotulska, K., and Jozwiak, S. (2011). Tuberous sclerosis complex: tumors and tumorigenesis. Int. J. Dermatol. 50, 13-20. doi: 10.1111/j.1365-4632.2010.04727.x

Boström, P., Wu, J., Jedrychowski, M. P., Korde, A., Ye, L., Lo, J. C., et al. (2012). A PGC1- $\alpha$-dependent myokine that drives brown-fat-like development of white fat and thermogenesis. Nature 481, 463-468. doi: 10.1038/nature10777

Braak, H., and Braak, E. (1991). Neuropathological stageing of Alzheimer-related changes. Acta Neuropathol. 82, 239-259. doi: 10.1007/bf00308809

Breitner, J. C. S. (1996). The role of anti-inflammatory drugs in the prevention and treatment of Alzheimer's disease. Annu. Rev. Med. 47, 401-411. doi: 10.1146/ annurev.med.47.1.401 
Briggs, J. P. (1999). Regulation of cyclooxygenase-2 expression in renal medulla by tonicity in vivo and in vitro. Am. J. Physiol. Renal Physiol. 277, 1-9. doi: 10.1152/ajprenal.1999.277.1.f1

Brocker, C., Thompson, D. C., and Vasiliou, V. (2012). The role of hyperosmotic stress in inflammation and disease. Biomol. Concepts 3, 345-364. doi: 10.1515/ bmc-2012-0001

Burg, M. B., Ferraris, J. D., and Dmitrieva, N. I. (2007). Cellular response to hyperosmotic stresses. Physiol. Rev. 87, 1441-1474. doi: 10.1152/physrev.00056. 2006

Burke, J. E., and Dennis, E. A. (2009). Phospholipase A 2 structure/function, mechanism, and signaling. J. Lipid Res. 50, 237-242. doi: 10.1194/jlr.R800033JLR200

Camacho, I. E., Serneels, L., Spittaels, K., Merchiers, P., Dominguez, D., and De Strooper, B. (2004). Peroxisome proliferator-activated receptor $\gamma$ induces a clearance mechanism for the amyloid- $\beta$ peptide. J. Neurosci. 24, 10908-10917. doi: 10.1523/JNEUROSCI.3987-04.2004

Chan, T. A., Morin, P. J., Vogelstein, B., and Kinzler, K. W. (1998). Mechanisms underlying nonsteroidal antiinflammatory drug-mediated apoptosis. Proc. Natl. Acad. Sci. U.S.A. 95, 681-686. doi: 10.1073/pnas.95.2.681

Choi, H., Chaiyamongkol, W., Doolittle, A. C., Johnson, Z. I., Gogate, S. S., Schoepflin, Z. R., et al. (2018). COX-2 expression mediated by calcium-TonEBP signaling axis under hyperosmotic conditions serves osmoprotective function in nucleus pulposus cells. J. Biol. Chem. 293, 869-8981. doi: 10.1074/jbc.RA117. 001167

Chuang, S., Lu, J., Lin, K., Long, C., Lee, Y., Hsiao, H., et al. (2019). Epigenetic regulation of COX-2 expression by DNA hypomethylation via NF- $\mathrm{BB}$ activation in ketamine-induced ulcerative cystitis. Int. J. Mol. Med. 44, 797-812. doi: 10.3892/ijmm.2019.4252

Clària, J. (2003). Cyclooxygenase-2 biology. Curr. Pharm. 9, 2177-2190. doi: 10. 2174/1381612033454054

Cohen, P., Levy, J. D., Zhang, Y., Frontini, A., Kolodin, D. P., Svensson, K. J., et al. (2014). Ablation of PRDM16 and beige adipose causes metabolic dysfunction and a subcutaneous to visceral fat switch. Cell 156, 304-316. doi: 10.1016/j.cell. 2013.12.021

Cuervo, A. M., Bergamini, E., Brunk, U. T., Dröge, W., Ffrench, M., and Terman, A. (2005). Autophagy and aging: the importance of maintaining "clean" cells. Autophagy 1, 131-140. doi: 10.4161/auto.1.3.2017

De Felice, F. G. (2013). Alzheimer's disease and insulin resistance: translating basic science into clinical applications. J. Clin. Invest. 123, 531-539. doi: 10.1172/ JCI64595

Delgoffe, G. M., Kole, T. P., Zheng, Y., Zarek, P. E., Matthews, K. L., Worley, P. F., et al. (2010). mTOR differentially regulates effector and regulatory $\mathrm{T}$ cell lineage commitment. Immunity 30, 832-844. doi: 10.1016/j.immuni.2009.04. 014.mTOR

Dello Russo, C., Lisi, L., Feinstein, D. L., and Navarra, P. (2013). mTOR kinase, a key player in the regulation of glial functions: relevance for the therapy of multiple sclerosis. Glia 61, 301-311. doi: 10.1002/glia.22433

Dibble, C. C., Elis, W., Menon, S., Qin, W., Klekota, J., Asara, J. M., et al. (2012). TBC1D7 Is a Third Subunit of the TSC1-TSC2 Complex Upstream of mTORC1. Mol. Cell 47, 535-546. doi: 10.1016/j.molcel.2012.06.009

Dinchuk, J. E., Car, B. D., Focht, R. J., Johnston, J. J., Jaffee, B. D., Covington, M. B., et al. (1995). Renal abnormalities and an altered inflammatory response in mice lacking cyclooxygenase II. Nature 378, 406-409. doi: 10.1038/378406a0

Efeyan, A., Zoncu, R., and Sabatini, D. M. (2013). Amino acids and mTORC1: from lysosomes to disease mTOR in growth control. Trends Mol. Med. 18, 524-533. doi: 10.1016/j.molmed.2012.05.007

Eltschinger, S., and Loewith, R. (2016). TOR Complexes and the Maintenance of Cellular Homeostasis. Trends Cell Biol. 26, 148-159. doi: 10.1016/j.tcb.2015.10. 003

Emmanuel, N., Ragunathan, S., Shan, Q., Wang, F., Giannakou, A., Huser, N., et al. (2017). Purine nucleotide availability regulates mTORC1 Activity through the Rheb GTPase. Cell Rep. 19, 2665-2680. doi: 10.1016/j.celrep.2017.05.043

Engelborghs, S., Gilles, C., Ivanoiu, A., and Vandewoude, M. (2014). Rationale and clinical data supporting nutritional intervention in Alzheimer's disease. Acta Clin. Belg. 69, 17-24. doi: 10.1179/0001551213Z.0000000006

Engelking, L. R. (Ed.) (2015). "Eicosanoids I," in Textbook of Veterinary Physiological Chemistry, (Cambridge, MA: Academic Press), 434-438. doi: 10. 1016/b978-0-12-391909-0.50068-2
Eriksen, J. L., Sagi, S. A., Smith, T. E., Weggen, S., Das, P., Mclendon, D. C., et al. (2003). NSAIDs and enantiomers of flurbiprofen target $\gamma$-secretase and lower A $\beta 42$ in vivo. J. Clin. Invest. 112, 440-449. doi: 10.1172/JCI200318162

Fan, S. J., Snell, C., Turley, H., Li, J. L., McCormick, R., Perera, S. M. W., et al. (2016). PAT4 levels control amino-acid sensitivity of rapamycin-resistant mTORC1 from the Golgi and affect clinical outcome in colorectal cancer. Oncogene 35, 3004-3015. doi: 10.1038/onc.2015.363

Favale, N. O., Casali, C. I., Lepera, L. G., Pescio, L. G., and Fernández-Tome, M. C. (2009). Hypertonic induction of COX2 expression requires TonEBP/NFAT5 in renal epithelial cells. Biochem. Biophy. Res. Comm. 381, 301-305. doi: 10.1016/ j.bbrc.2008.12.189

Favale, N. O., Sterin Speziale, N. B., and Fernández Tome, M. C. (2007). Hypertonic-induced lamin $\mathrm{A} / \mathrm{C}$ synthesis and distribution to nucleoplasmic speckles is mediated by TonEBP/NFAT5 transcriptional activator. Biochem. Biophys. Res. Comm. 364, 443-449. doi: 10.1016/j.bbrc.2007.10.054

Ferreira, L. S. S., Fernandes, C. S., Vieira, M. N. N., and De Felice, F. G. (2018). Insulin resistance in Alzheimer's disease. Front. Neurosci. 12:830. doi: 10.3389/ fnins.2018.00830

Fjaere, E., Aune, U. L., Røen, K., Keenan, A. H., Ma, T., Borkowski, K., et al. (2014). Indomethacin treatment prevents high fat diet-induced obesity and insulin resistance but not glucose intolerance in C57BL/6J mice. J. Biol. Chem. 289, 16032-16045. doi: 10.1074/jbc.M113.525220

Forny-Germano, L., De Felice, F. G., and Do Nascimento Vieira, M. N. (2019). The role of leptin and adiponectin in obesity-associated cognitive decline and Alzheimer's disease*. Front.Neurosci. 13:1027. doi: 10.3389/fnins.2018. 01027

Fukunaga, K., Kohli, P., Bonnans, C., Fredenburgh, L. E., and Levy, B. D. (2005). Cyclooxygenase 2 Plays a Pivotal Role in the Resolution of Acute Lung Injury. J. Immunol. 174, 5033-5039. doi: 10.4049/jimmunol.174.8.5033

Gadducci, A., Tana, R., Cosio, S., Fanucchi, A., and Genazzani, A. R. (2008). Molecular target therapies in endometrial cancer: from the basic research to the clinic. Gynecol. Endocrinol. 24, 239-249. doi: 10.1080/095135908019 53556

Goberdhan, D. C. I. (2010). Intracellular amino acid sensing and mTORC1regulated growth: new ways to block an old target? Curr. Opin. Invest. Drugs $11,1360-1367$.

Goberdhan, D. C. I., Meredith, D., Boyd, C. A. R., and Wilson, C. (2005). PATrelated amino acid transporters regulate growth via a novel mechanism that does not require bulk transport of amino acids. Development 132, 2365-2375. doi: 10.1242/dev.01821

Goberdhan, D. C. I., Wilson, C., and Harris, A. L. (2016). Amino Acid Sensing by mTORC1: intracellular transporters mark the spot. Cell Metab. 23, 580-589. doi: 10.1016/j.cmet.2016.03.013

Greenhough, A., Smartt, H. J. M., Moore, A. E., Roberts, H. R., Williams, A. C., Paraskeva, C., et al. (2009). The COX-2/PGE2 pathway: key roles in the hallmarks of cancer and adaptation to the tumour microenvironment. Carcinogenesis 30, 377-386. doi: 10.1093/carcin/bgp014

Grundke-Iqbal, I., Iqbal, K., and Tung, Y. C. (1986). Abnormal phosphorylation of the microtubule-associated protein $\tau$ (tau) in Alzheimer cytoskeletal pathology. Proc. Natl. Acad. Sci. U.S.A. 83, 44913-44917. doi: 10.1073/pnas.83.13.4913

Guan, Y., Chang, M., Cho, W., Zhang, Y., Redha, R., Davis, L., et al. (1997). Cloning, expression, and regulation cyclooxygenase-2 in renal medullary of rabbit interstitial cells. Am. J. Physiol. 273, F18-F26. doi: 10.1152/ajprenal.1997. 273.1.F18

Guba, M., Breitenbuch, P., von, Steinabauer, M., Koehl, G., Flegel, S., Hornung, M., et al. (2002). Rapamycin inhibits primary and metastatic tumor growth by antiangiogenesis: involvement of vascular endothelial growth factor. Nat. Med. 8, 128-135. doi: 10.1038/nm0202-128

Hahr, J. Y. (2015). Physiology of the Alzheimer's disease. Med. Hypotheses 85, 944-946. doi: 10.1016/j.mehy.2015.09.005

Hanna, V. S., and Hafez, E. A. A. (2018). Synopsis of arachidonic acid metabolism: a review. J. Adv. Res. 11, 23-32. doi: 10.1016/j.jare.2018.03.005

Harms, M., and Seale, P. (2013). Brown and beige fat: development, function and therapeutic potential. Nat. Med. 19, 1252-1263. doi: 10.1038/nm.3361

Harris, R. C., McKanna, J. A., Akai, Y., Jacobson, H. R., Dubois, R. N., and Breyer, M. D. (1994). Cyclooxygenase-2 is associated with the macula densa of rat kidney and increases with salt restriction. J. Clin. Invest. 94, 2504-2510. doi: $10.1172 /$ JCI117620 
Haung Yu, W., Cuervo, A. M., Kumar, A., Peterhoff, C. M., Schmidt, S. D., Lee, J. H., et al. (2005). Macroautophagy - A novel $\beta$-amyloid peptide-generating pathway activated in Alzheimer's disease. J. Cell Biol. 171, 87-98. doi: 10.1083/ jcb.200505082

Heafield, M. T., Fearn, S., Steventon, G. B., Waring, R. H., Williams, A. C., and Sturman, S. G. (1990). Plasma cysteine and sulphate levels in patients with motor neurone, Parkinson's and Alzheimer's disease. Neurosci. Lett. 110, 216-220. doi: 10.1016/0304-3940(90)90814-P

Ho, L., Purohit, D., Haroutunian, V., Luterman, J. D., Willis, F., Naslund, J., et al. (2001). Neuronal cyclooxygenase 2 expression in the hippocampal formation as a function of the clinical progression of Alzheimer disease. Arch. Neurol. 58, 487-492. doi: 10.1001/archneur.58.3.487

Hölscher, C. (1995). Inhibitors of cyclooxygenases produce amnesia for a passive avoidance task in the chick. Eur. J. Neurosci. 7, 1360-1365. doi: 10.1111/j.14609568.1995.tb01127.x

Hoozemans, J., Rozemuller, J., van Haastert, E., Veerhuis, R., and Eikelenboom, P. (2008). Cyclooxygenase-1 and -2 in the different stages of alzheimers disease pathology. Curr. Pharm. Des. 14, 1419-1427. doi: 10.2174/138161208784480171

Hoozemans, J. J. M., Brückner, M. K., Rozemuller, A. J. M., Veerhuis, R., Eikelenboom, P., and Arendt, T. (2002). Cyclin D1 and cyclin E are co-localized with cyclo-oxygenase 2 (COX-2) in pyramidal neurons in Alzheimer disease temporal cortex. J. Neuropathol. Exp. Neurol. 61, 678-688. doi: 10.1093/jnen/ 61.8.678

Hoozemans, J. J. M., Rozemuller, A. J. M., Janssen, I., De Groot, C. J. A., Veerhuis, R., and Eikelenboom, P. (2001). Cyclooxygenase expression in microglia and neurons in Alzheimer's disease and control brain. Acta Neuropathol. 101, 2-8. doi: 10.1016/s0197-4580(00)82335-0

Hoozemans, J. J. M., Veerhuis, R., Rozemuller, A. J. M., Arendt, T., and Eikelenboom, P. (2004). Neuronal COX-2 expression and phosphorylation of $\mathrm{pRb}$ precede $\mathrm{p} 38 \mathrm{MAPK}$ activation and neurofibrillary changes in AD temporal cortex. Neurobiol. Dis. 15, 492-499. doi: 10.1016/j.nbd.2003.11.028

Hoozemans, J. J. M., Veerhuis, R., Rozemuller, J. M., and Eikelenboom, P. (2006). Neuroinflammation and regeneration in the early stages of Alzheimer's disease pathology. Int. J. Dev. Neurosci. 24, 157-165. doi: 10.1016/j.ijdevneu.2005.11. 001

Howie, D., Waldmann, H., and Cobbold, S. P. (2014). Nutrient sensing via mTOR in T cells maintains a tolerogenic microenvironment. Front. Immunol. 5:409. doi: 10.3389/fimmu.2014.00409

Hoxhaj, G., Hughes-Hallett, J., Timson, R. C., Ilagan, E., Yuan, M., Asara, J. M., et al. (2017). The mTORC1 signaling network senses changes in cellular purine nucleotide levels. Cell Rep. 21, 1331-1346. doi: 10.1016/j.celrep.2017.10.029

Hsu, A. L., Ching, T. T., Wang, D. S., Song, X., Rangnekar, V. M., and Chen, C. S. (2000). The cyclooxygenase-2 inhibitor celecoxib induces apoptosis by blocking Akt activation in human prostate cancer cells independently of Bcl-2. J. Biol. Chem. 275, 11397-11403. doi: 10.1074/jbc.275.15.11397

Hwang, D., Scollard, D., Byrne, J., and Levine, E. (1998). Expression of cyclooxygenase-1 and cyclooxygenase- 2 in human breast cancer. J. Natl. Cancer Inst. 90, 455-460. doi: 10.1093/jnci/90.6.455

Iglesias-Bartolome, R., Patel, V., Cotrim, A., Leelahavanichkul, K., Molinolo, A. A., Mitchell, J. B., et al. (2012). mTOR inhibition prevents epithelial stem cell senescence and protects from radiation-induced mucositis. Cell Stem Cell 11, 401-414. doi: 10.1016/j.stem.2012.06.007

Jae, H. N., Jeon, Y. T., Park, I. A., Kang, D., Jae, W. K., Park, N. H., et al. (2009). Expression of mTOR protein and its clinical significance in endometrial cancer. Med. Sci. Monit. 15, 301-305.

Jewell, J. L., Kim, Y. C., Russell, R. C., Yu, F.-X., Park, H. W., Plouffe, S. W., et al. (2015). Differential regulation of mTORC1 by leucine and glutamine. Sci. Exp. 347, 194-198. doi: 10.1126/science.1259472

Jung, Y., Isaacs, J. S., Lee, S., Trepel, J., and Neckers, L. (2003). IL-1 $\beta$ mediated up-regulation of HIF- $1 \alpha$ via an NFkB/COX- 2 pathway identifies HIF-1 as a critical link between inflammation and oncogenesis. FASEB J. 17, 2115-2117. doi: 10.1096/fj.03-0329fje

Kang, Y.-J., Mbonye, U. R., DeLong, C. J., Wada, M., and Smith, W. L. (2007). Regulation of Intracellular Cyclooxygenase Levels by Gene Transcription and Protein Degradation. Prog. Lipid Res. 46, 108-125. doi: 10.1016/j.plipres.2007. 01.001
Kaufmann, W. E., Andreasson, K. I., Isakson, P. C., and Worley, P. F. (1997). Cyclooxygenases and the central nervous system. Prostaglandins 54, 601-624. doi: 10.1016/S0090-6980(97)00128-7

Khamzina, L., Veilleux, A., Bergeron, S., and Marette, A. (2005). Increased activation of the mammalian target of rapamycin pathway in liver and skeletal muscle of obese rats: possible involvement in obesity-linked insulin resistance. Endocrinology 146, 1473-1481. doi: 10.1210/en.2004-0921

Kikuchi, T., Itoh, F., Toyota, M., Suzuki, H., Yamamoto, H., Fujita, M., et al. (2002). Aberrant methylation and histone deacetylation of cyclooxygenase 2 in gastric cancer. Int. J. Cancer 97, 272-277. doi: 10.1002/ijc.1612

Kim, S. H., Yan, Y. B., and Zhou, H. M. (2006). Role of osmolytes as chemical chaperones during the refolding of aminoacylase. Biochem. Cell Biol. 84, 30-38. doi: $10.1139 / 005-148$

Kitamura, Y., Shimohama, S., Koike, H., Kakimura, J. I., Matsuoka, Y., Nomura, Y., et al. (1999). Increased expression of cyclooxygenases and peroxisome proliferator-activated receptor- $\gamma$ in Alzheimer's disease brains. Biochem. Biophys. Res. Commun. 254, 582-586. doi: 10.1006/bbrc.1998.9981

Kotilinek, L. A., Westerman, M. A., Wang, Q., Panizzon, K., Lim, G. P., Simonyi, A., et al. (2008). Cyclooxygenase- 2 inhibition improves amyloid- $\beta$-mediated suppression of memory and synaptic plasticity. Brain 131, 651-664. doi: 10. 1093/brain/awn008

Kwiatkowski, D. J., and Manning, B. D. (2014). Molecular basis of giant cells in tuberous sclerosis complex. N. Engl. J. Med. 371, 778-780. doi: 10.1056/ NEJMcibr1406613

Laplante, M., and Sabatini, D. M. (2012). MTOR signaling in growth control and disease. Cell 149, 274-293. doi: 10.1016/j.cell.2012.03.017

Latham, C. F., Osborne, S. L., Cryle, M. J., and Meunier, F. A. (2007). Arachidonic acid potentiates exocytosis and allows neuronal SNARE complex to interact with Munc18a. J. Neurochem. 100, 1543-1554. doi: 10.1111/j.1471-4159.2006. 04286.x

Lee, K., Gudapati, P., Dragovic, S., Spencer, C., Killeen, N., Magnuson, M. A., et al. (2010). Mammalian target of rapamycin protein complex 2 regulates differentiation of Th1 and Th2 cell subsets via distinct signaling pathways. Immunity 32, 743-753. doi: 10.1016/j.immuni.2010.06.002

Li, D., Misialek, J. R., Boerwinkle, E., Gottesman, R. F., Sharrett, A. R., Mosley, T. H., et al. (2016). Plasma phospholipids and prevalence of mild cognitive impairment and/or dementia in the ARIC Neurocognitive Study (ARIC-NCS). Alzheimer's Dement 3, 73-82. doi: 10.1016/j.dadm.2016.02.008

Li, H., Jin, F., Jiang, K., Ji, S., Wang, L., Ni, Z., et al. (2016). mTORC1-mediated downregulation of COX2 restrains tumor growth caused by TSC2 deficiency. Oncotarget 7, 28435-28447. doi: 10.18632/oncotarget.8633

Lipskar, A. M., Glick, R. D., Huang, J., Fisher, J. C., DeVoti, J., Pica, R., et al. (2009). Cyclooxygenase 2 mediates the antiangiogenic effect of rapamycin in Ewing sarcoma. J. Pediatr. Surg. 44, 1139-1147. doi: 10.1016/j.jpedsurg.2009. 02.037

Liu, D., Bordicchia, M., Zhang, C., Fang, H., Wei, W., Li, J., et al. (2016). Activation of mTORC1 is essential for Badrenergic stimulation of adipose browning. J. Clin. Invest. 126, 1704-1716. doi: 10.1172/JCI83532

Liu, M., Bai, J., He, S., Villarreal, R., Hu, D., Zhang, C., et al. (2014). Grb10 promotes lipolysis and thermogenesis by phosphorylation-dependent feedback inhibition of mTORC1. Cell Metab. 19, 967-980. doi: 10.1016/j.cmet.2014. 03.018

Liu, X., Yao, S., Kirschenbaum, A., and Levine, A. C. (1998). NS398, a Selective Cyclooxygenase-2 inhibitor, induces apoptosis and down- regulates bcl-2 expression in LNCaP cells. Am. Ass. Cancer Res. 58, 4245-4249.

López-otín, C., Blasco, M. A., Partridge, L., Serrano, M., and Kroemer, G. (2013). The hallmarks of aging longevity. Cell 153, 1194-1217. doi: 10.1016/j.cell.2013. 05.039.The

Luo, J., Wärmländer, S. K. T. S., Gräslund, A., and Abrahams, J. P. (2016). Cross-interactions between the Alzheimer disease amyloid- $\beta$ peptide and other amyloid proteins: a further aspect of the amyloid cascade hypothesis. J. Biol. Chem. 291, 16485-16493. doi: 10.1074/jbc.R116.714576

Ma, X., Yang, Q., Wilson, K. T., Kundu, N., Meltzer, S. J., and Fulton, A. M. (2004). Promoter methylation regulates cyclooxygenase expression in breast cancer. Breast Cancer Res. 6, 316-321. doi: 10.1186/bcr793

Macknight, A. D. C. (1988). Principles of cell volume regulation. Renal Physiol. Biochem. 11, 114-141. doi: 10.1159/000173158 
Madsen, L., Pedersen, L. M., Liaset, B., Ma, T., Petersen, R. K., Van Den Berg, S., et al. (2008). cAMP-dependent signaling regulates the adipogenic effect of $n$ 6 polyunsaturated fatty acids. J. Biol. Chem. 283, 7196-7205. doi: 10.1074/jbc. M707775200

Majumder, S., Richardson, A., Strong, R., and Oddo, S. (2011). Inducing autophagy by rapamycin before, but not after, the formation of plaques and tangles ameliorates cognitive deficits. PLoS One 6:e25416. doi: 10.1371/journal.pone. 0025416

Maskrey, B. H., Megson, I. L., Whitfield, P. D., and Rossi, A. G. (2011). Mechanisms of resolution of inflammation: a focus on cardiovascular disease. Arterioscler. Thromb. Vasc. Biol. 31, 1001-1006. doi: 10.1161/ATVBAHA.110.213850

Mattsson, J. S. M., Bergman, B., Grinberg, M., Edlund, K., Marincevic, M., Jirström, K., et al. (2015). Prognostic impact of COX-2 in non-small cell lung cancer: a comprehensive compartment-specific evaluation of tumor and stromal cell expression. Cancer Lett. 356, 837-845. doi: 10.1016/j.canlet.2014.10.032

Miettinen, S., Fusco, F. R., Yrjänheikki, J., Keinänen, R., Hirvonen, T., Roivainen, R., et al. (1997). Spreading depression and focal brain ischemia induce cyclooxygenase-2 in cortical neurons through N-methyl-D-aspartic acidreceptors and phospholipase A2. Proc. Natl. Acad. Sci. U.S.A. 94, 6500-6505. doi: 10.1073/pnas.94.12.6500

Minghetti, L. (2004). Cyclooxygenase-2 (COX-2) in inflammatory and degenerative brain diseases. J. Neuropathol. Exp. Neurol. 63, 901-910. doi: 10.1093/jnen/63.9.901

Moavero, R., Romagnoli, G., Graziola, F., and Curatolo, P. (2015). Mammalian target of rapamycin inhibitors and life-threatening conditions in tuberous sclerosis complex. Semin. Pediatr. Neurol. 22, 282-294. doi: 10.1016/j.spen. 2015.10.006

Moeckel, G. W., Zhang, L., Fogo, A. B., Hao, C.-M., and Breyer, M. D. (2003). COX2-activity promotes organic osmolyte accumulation and adaptation of Renal Medullary Interstitial Cells to hypertonic stress. J. Biol. Chem. 278, 19352-19357. doi: 10.1074/jbc.M302209200

Morihara, T., Chu, T., Ubeda, O., Beech, W., and Cole, G. M. (2002). Selective inhibition of A 342 production by NSAID R-enantiomers. J. Neurochem. 83, 1009-1012. doi: 10.1046/j.1471-4159.2002.01195.x

Mueed, Z., Tandon, P., Maurya, S. K., Deval, R., Kamal, M. A., and Poddar, N. K. (2019). Tau and mTOR: the hotspots for multifarious diseases in Alzheimer's development. Front. Neurosci. 13:1017. doi: 10.3389/fnins.2018. 01017

Murakami, M., Kuwata, H., Amakasu, Y., Shimbara, S., Nakatani, Y., Atsumi, G. I., et al. (1997). Prostaglandin E2 amplifies cytosolic phospholipase A2- and cyclooxygenase-2-dependent delayed prostaglandin E2 generation in mouse osteoblastic cells. Enhancement by secretory phospholipase A2. J. Bio. Chem. 272, 19891-19897. doi: 10.1074/jbc.272.32.19891

Ortega-Gómez, A., Perretti, M., and Soehnlein, O. (2013). Resolution of inflammation: an integrated view. EMBO Mol. Med. 5, 661-674. doi: 10.1002/ emmm.201202382

Pan, X., Nasaruddin, M. B., Elliott, C. T., McGuinness, B., Passmore, A. P., Kehoe, P. G., et al. (2016). Alzheimer's disease-like pathology has transient effects on the brain and blood metabolome. Neurobiol. Aging 38, 151-163. doi: 10.1016/j. neurobiolaging.2015.11.014

Pandey, M., Prakash, O., Santhi, W. S., Soumithran, C. S., and Pillai, R. M. (2008). Overexpression of COX-2 gene in oral cancer is independent of stage of disease and degree of differentiation. Int. J. Oral Maxillofac. Surg. 37, 379-383. doi: 10.1016/j.ijom.2008.01.004

Papadopoli, D., Boulay, K., Kazak, L., Pollak, M., Mallette, F., Topisirovic, I., et al. (2019). mTOR as a central regulator of lifespan and aging. F1000Res 8:998. doi: 10.12688/f1000research.17196.1

Pasinetti, G. M., and Aisen, P. S. (1998). Cyclooxygenase-2 expression is increased in frontal cortex of Alzheimer's disease brain. Science 87, 319-324. doi: 10.1016/ S0306-4522(98)00218-8

Pei, J. J., Björkdahl, C., Zhang, H., Zhou, X., and Winblad, B. (2008). p70 S6 kinase and tau in Alzheimer's disease. J. Alzheimer's Dis. 14, 385-392. doi: 10.3233/JAD-2008- 14405

Pei, J. J., and Hugon, J. (2008). mTOR-dependent signalling in Alzheimer's disease. J. Cell. Mol. Med. 12, 2525-2532. doi: 10.1111/j.1582-4934.2008.00509.x

Perluigi, M., Di Domenico, F., and Butterfield, D. A. (2015). mTOR signaling in aging and neurodegeneration: at the crossroad between metabolism dysfunction and impairment of autophagy. Neurobiol. Dis. 84, 39-49. doi: 10. 1016/j.nbd.2015.03.014

Pesini, A., Iglesias, E., Bayona-Bafaluy, M. P., Garrido-Pérez, N., Meade, P., Gaudó, P., et al. (2019). Brain pyrimidine nucleotide synthesis and Alzheimer disease. Aging 11, 8433-8462. doi: 10.18632/aging. 102328

Phung, T. L., Ziv, K., Dabydeen, D., Eyiah-Mensah, G., Riveros, M., Perruzzi, C., et al. (2006). Pathological angiogenesis is induced by sustained Akt signaling and inhibited by rapamycin. Cancer Cell 10, 159-170. doi: 10.1016/j.ccr.2006. 07.003

Polak, P., Cybulski, N., Feige, J. N., Auwerx, J., Rüegg, M. A., and Hall, M. N. (2008). Adipose-specific knockout of raptor results in lean mice with enhanced mitochondrial respiration. Cell Metab. 8, 399-410. doi: 10.1016/j.cmet.2008.09. 003

Rao, R., Hao, C. M., and Breyer, M. D. (2004). Hypertonic stress activates glycogen synthase Kinase $3 \beta$-mediated apoptosis of renal medullary interstitial cells, suppressing an NFкB-driven Cyclooxygenase-2-dependent survival pathway. J. Biol. Chem. 279, 3949-3955. doi: 10.1074/jbc.M309325200

Reddy, S. T., Wadleigh, D. J., and Herschman, H. R. (2000). Transcriptional regulation of the cyclooxygenase-2 gene in activated mast cells. J. Biol. Chem. 275, 3107-3113. doi: 10.1074/jbc.275.5.3107

Ritchie, C. W., Bajwa, J., Coleman, G., Hope, K., Jones, R. W., Lawton, M., et al. (2014). Souvenaid\$: a new approach to management of early Alzheimer's disease. J. Nutr. Health Aging 18, 291-299. doi: 10.1007/s12603-013-0411-2

Rousseau, A., and Bertolotti, A. (2016). An evolutionarily conserved pathway controls proteasome homeostasis. Nature 536, 184-189. doi: 10.1038/ nature 18943

Rouzer, C. A., and Marnett, L. J. (2009). Cyclooxygenases: structural and functional insights. J. Lipid Res. 50, 29-34. doi: 10.1194/jlr.R800042-JLR200

Sauer, S., Bruno, L., Hertweck, A., Finlay, D., Leleu, M., Spivakov, M., et al. (2008). $\mathrm{T}$ cell receptor signaling controls Foxp3 expression via PI3K, Akt, and mTOR. Proc. Natl. Acad. Sci. U.S.A. 105, 7797-7802. doi: 10.1073/pnas.0800928105

Saxton, R. A., and Sabatini, D. M. (2017). mTOR signaling in growth, metabolism and disease. Cell 168, 960-976. doi: 10.1016/j.cell.2017.02.004

Schepis, C. (2016). "The tuberous sclerosis complex," in Dermatological Cryosurgery and Cryotherapy, eds W. Abramovits, G. Graham, Y. Har-Shai, and R. Strumia (London: Springer), 615-617. doi: 10.1007/978-1-4471-6765-5_120

Schubert, D., and Piasecki, D. (2001). Oxidative glutamate toxicity can be a component of the excitotoxicity cascade. J. Neurosci. 21, 7455-7462. doi: 10. 1523/jneurosci.21-19-07455.2001

Shacka, J. J., Roth, K. A., and Zhang, J. (2008). The autophagy-lysosomal degradation pathway: role in neurodegenerative disease and therapy. Front. Biosci. 13:718-736. doi: 10.2741/2714

Shafei, M. A., Harris, M., and Conway, M. E. (2017). Divergent metabolic regulation of autophagy and mTORC1-early events in Alzheimer's disease? Front. Aging Neurosci. 9:173. doi: 10.3389/fnagi.2017.00173

Shafi, O. (2016). Inverse relationship between Alzheimer's disease and cancer, and other factors contributing to Alzheimer's disease: a systematic review. $B M C$ Neurol. 16:765. doi: 10.1186/s12883-016-0765-2

Sheng, H., Shao, J., Morrow, J. D., Beauchamp, R. D., and DuBois, R. N. (1998). Modulation of apoptosis and Bcl-2 expression by prostaglandin E2 in human colon cancer cells. Cancer Res. 58, 362-366.

Slomovitz, B. M., and Coleman, R. L. (2012). The PI3K/AKT/mTOR pathway as a therapeutic target in endometrial cancer. Clin. Cancer Res. 18, 5856-5864. doi: 10.1158/1078-0432.CCR-12-0662

Smyth, E. M., Grosser, T., Wang, M., Yu, Y., and FitzGerald, G. A. (2009). Prostanoids in health and disease. J. Lipid Res. 50, 423-428. doi: 10.1194/jlr. R800094-JLR200

Sommer, A., Winner, B., and Prots, I. (2017). The Trojan horse Neuroinflammatory impact of $\mathrm{T}$ cells in neurodegenerative diseases. Mol. Neurodegen. 12, 1-10. doi: 10.1186/s13024-017-0222-8

Spaggiari, G. M., Capobianco, A., Abdelrazik, H., Becchetti, F., Mingari, M. C., and Moretta, L. (2008). Mesenchymal stem cells inhibit natural killer-cell proliferation, cytotoxicity, and cytokine production: role of indoleamine 2,3dioxygenase and prostaglandin E2. Blood 111, 1327-1333. doi: 10.1182/blood2007-02-074997

Spilman, P., Podlutskaya, N., Hart, M. J., Debnath, J., Gorostiza, O., Bredesen, D., et al. (2010). Inhibition of mTOR by rapamycin abolishes cognitive deficits and 
reduces amyloid- $\beta$ levels in a mouse model of alzheimer's disease. PLoS One 5:e9979. doi: 10.1371/journal.pone.0009979

Stewart, W. F., Kawas, C., Corrada, M., and Metter, E. J. (1997). Risk of Alzheimer's disease and duration of NSAID use. Neurology 48, 626-632. doi: 10.1212/WNL. 48.3.626

Sun, G. Y., Shelat, P. B., Jensen, M. B., He, Y., Sun, A. Y., and Simonyi, A. (2010). Phospholipases A2 and inflammatory responses in the central nervous system. Neuro Mol. Med. 12, 133-148. doi: 10.1007/s12017-009-8092-Z

Tang, Z., Bereczki, E., Zhang, H., Wang, S., Li, C., Ji, X., et al. (2013). Mammalian target of rapamycin (mTor) mediates tau protein dyshomeostasis: implication for Alzheimer disease. J. Biol. Chem. 288, 15556-15570. doi: 10.1074/jbc.M112. 435123

Tang, Z., Ioja, E., Bereczki, E., Hultenby, K., Li, C., Guan, Z., et al. (2015). MTor mediates tau localization and secretion: implication for Alzheimer's disease. Biochim. Biophys. Acta 1853, 1646-1657. doi: 10.1016/j.bbamcr.2015.03.003

Thomas, M. H., Pelleieux, S., Vitale, N., and Olivier, J. L. (2016). Arachidonic acid in Alzheimer' s disease. J. Neurol. Neuromed. 1, 1-6.

Tomimoto, H., Akiguchi, I., Wakita, H., Lin, J. X., and Budka, H. (2000). Cyclooxygenase- 2 is induced in microglia during chronic cerebral ischemia in humans. Acta Neuropathol. 99, 26-30. doi: 10.1007/PL00007402

Tran, C. M., Mukherjee, S., Ye, L., Frederick, D. W., Kissig, M., Davis, J. G., et al. (2016). Rapamycin blocks induction of the thermogenic program in white adipose tissue. Diabetes Metab. Res. Rev. 65, 927-941. doi: 10.2337/db15-0502

Tsujii, M., and DuBois, R. N. (1995). Alterations in cellular adhesion and apoptosis in epithelial cells overexpressing prostaglandin endoperoxide synthase 2 . Cell 83, 493-501. doi: 10.1016/0092-8674(95)90127-2

Tynkkynen, J., Chouraki, V., van der Lee, S. J., Hernesniemi, J., Yang, Q., Li, S., et al. (2018). Association of branched-chain amino acids and other circulating metabolites with risk of incident dementia and Alzheimer's disease: a prospective study in eight cohorts. Alzheimer's Dement 14, 723-733. doi: 10.1016/j.jalz.2018.01.003

Uddin, M. S., Stachowiak, A., Al Mamun, A., Tzvetkov, N. T., Takeda, S., Atanasov, A. G., et al. (2018). Autophagy and Alzheimer's disease: from molecular mechanisms to therapeutic implications. Front. Aging Neurosci. 10:4. doi: 10. 3389/fnagi.2018.00004

Um, S. H., Frigerio, F., Watanabe, M., Picard, F., Joaquin, M., Sticker, M., et al. (2004). Absence of S6K1 protects against age- and diet-induced obesity while enhancing insulin sensitivity. Nature 431, 200-205. doi: 10.1038/nature 02866

Wada, S., Neinast, M., Jang, C., Ibrahim, Y. H., Lee, G., Babu, A., et al. (2016). The tumor suppressor FLCN mediates an alternate mTOR pathway to regulate browning of adipose tissue. Genes Dev. 30, 2551-2564. doi: 10.1101/gad.287953. 116

Walsh, D. T., Perry, V. H., and Minghetti, L. (2000). Cyclooxygenase-2 is highly expressed in microglial-like cells in a murine model of prion disease. Glia 29, 392-396. doi: 10.1002/(SICI)1098-1136(20000215)29:4(392:AID-GLIA10(3.0. $\mathrm{CO} ; 2-\mathrm{C}$

Wang, B., Lin, Y., Hu, Y., Shan, W., Liu, S., Xu, Y., et al. (2017). MTOR inhibition improves the immunomodulatory properties of human bone marrow mesenchymal stem cells by inducing COX-2 and PGE2. Stem Cell Res. Ther. 8, 1-13. doi: 10.1186/s13287-017-0744-6
Weggen, S., Eriksen, J. L., Das, P., Sagi, S. A., Wang, R., Pietrzik, C. U., et al. (2001). A subset of NSAIDs lower amyloidogenic A $\beta 42$ independently of cyclooxygenase activity. Nature 414, 212-216. doi: 10.1038/3510 2591

Wijayasinghe, Y. S., Tyagi, A., and Poddar, N. K. (2017). "Regulation of Cell Volume by Osmolytes," in Cellular Osmolytes: From Chaperoning Protein Folding to Clinical Perspectives, eds L. Rajendrakumar Singh and T. Dar (Singapore: Springer), 195-228. doi: 10.1007/978-981-10-3707-8_9

Williams, C. S., Mann, M., and DuBois, R. N. (1999). The role of cyclooxygenases in inflammation, cancer, and development. Oncogene 18, 7908-7916. doi: 10. 1038/sj.onc. 1203286

Wu Chen, R., Zhang, Y., Rose, M. E., and Graham, S. H. (2004). Cyclooxygenase-2 activity contributes to neuronal expression of cyclin D1 after anoxia/ischemia in vitro and in vivo. Mol. Brain Res. 132, 31-37. doi: 10.1016/j.molbrainres.2004. 08.020

Wyss-Coray, T., and Mucke, L. (2002). Inflammation in neurodegenerative disease - A double-edged sword. Neuron 35, 419-432. doi: 10.1016/S0896-6273(02) 00794-8

Xiang, Z., Ho, L., Valdellon, J., Borchelt, D., Kelley, K., Spielman, L., et al. (2002). Cyclooxygenase (COX)-2 and cell cycle activity in a transgenic mouse model of Alzheimer's disease neuropathology. Neurobiol. Aging 23, 327-334. doi: 10. 1016/S0197-4580(01)00282-2

Xu, Z., You, W., Zhou, Y., Chen, W., Wang, Y., and Shan, T. (2019). Cold-induced lipid dynamics and transcriptional programs in white adipose tissue. BMC Biol. 17:693. doi: 10.1186/s12915-019-0693-x

Yang, F., and Bleich, D. (2004). Transcriptional regulation of cyclooxygenase-2 gene in pancreatic $\beta$-cells. J. Biol. Chem. 279, 35403-35411. doi: 10.1074/jbc. M404055200

Yang, T., Huang, Y., Heasley, L. E., Berl, T., Schnermann, J. B., and Briggs, J. P. (2000). MAPK mediation of hypertonicity-stimulated cyclooxygenase-2 expression in renal medullary collecting duct cells. J. Biol. Chem. 275, 2328123286. doi: 10.1074/jbc.M910237199

Zhang, X., Luo, Y., Wang, C., Ding, X., Yang, X., Wu, D., et al. (2018). Adipose mTORC1 Suppresses Prostaglandin Signaling and Beige Adipogenesis via the CRTC2-COX-2 Pathway. Cell Rep. 24, 3180-3193. doi: 10.1016/j.celrep.2018. 08.055

Zhao, J., Zhai, B., Gygi, S. P., and Goldberg, A. L. (2015). MTOR inhibition activates overall protein degradation by the ubiquitin proteasome system as well as by autophagy. Proc. Natl. Acad. Sci. U.S.A. 112, 15790-15797. doi: 10.1073/pnas. 1521919112

Conflict of Interest: The authors declare that the research was conducted in the absence of any commercial or financial relationships that could be construed as a potential conflict of interest.

Copyright (c) 2020 Tyagi, Kamal and Poddar. This is an open-access article distributed under the terms of the Creative Commons Attribution License (CC BY). The use, distribution or reproduction in other forums is permitted, provided the original author(s) and the copyright owner(s) are credited and that the original publication in this journal is cited, in accordance with accepted academic practice. No use, distribution or reproduction is permitted which does not comply with these terms. 